\title{
FAK Is Required for Schwann Cell Spreading on Immature Basal Lamina to Coordinate the Radial Sorting of Peripheral Axons with Myelination
}

\author{
Matthew Grove and Peter J. Brophy \\ Centre for Neuroregeneration, University of Edinburgh, Edinburgh EH16 4SB, United Kingdom
}

Without Focal Adhesion Kinase (FAK), developing murine Schwann cells (SCs) proliferate poorly, sort axons inefficiently, and cannot myelinate peripheral nerves. Here we show that FAK is required for the development of SCs when their basal lamina (BL) is fragmentary, but not when it is mature in vivo. Mutant SCs fail to spread on fragmentary BL during development in vivo, and this is phenocopied by SCs lacking functional FAK on low laminin (LN) in vitro. Furthermore, SCs without functional FAK initiate differentiation prematurely, both in vivo and in vitro. In contrast to their behavior on high levels of LN, SCs lacking functional FAK grown on low LN display reduced spreading, proliferation, and indicators of contractility (i.e., stress fibers, arcs, and focal adhesions) and are primed to differentiate. Growth of SCs lacking functional FAK on increasing $\mathrm{LN}$ concentrations in vitro revealed that differentiation is not regulated by $\mathrm{G}_{1}$ arrest but rather by cell spreading and the level of contractile actomyosin. The importance of FAK as a critical regulator of the specific response of developing SCs to fragmentary BL was supported by the ability of adult FAK mutant SCs to remyelinate demyelinated adult nerves on mature BL in vivo. We conclude that FAK promotes the spreading and actomyosin contractility of immature SCs on fragmentary BL, thus maintaining their proliferation, and preventing differentiation until they reach high density, thereby promoting radial sorting. Hence, FAK has a critical role in the response of SCs to limiting BL by promoting proliferation and preventing premature SC differentiation.

Key words: basal lamina; FAK; myelination; Schwann cell

\section{Introduction}

During embryonic development, immature Schwann cells (SCs) differentiate to envelop their associated axon fascicles and form a shared basal lamina (BL). Concomitantly, immature SCs proliferate and extend cytoplasmic processes into axon bundles to radially sort large caliber axons into 1:1 promyelinating relationships (Peters and Muir, 1959; Webster, 1971; Martin and Webster, 1973; Jessen and Mirsky, 2005). The BL has a key role in SC development because it contains laminins (LNs) 211 and 411, which promote SC proliferation and radial sorting (Yang et al., 2005; Yu et al., 2005). Although initially thin and discontinuous, the BL ultimately consolidates into a thick intact layer around myelinating SCs (Webster et al., 1973).

SCs can interact with LNs in the BL through integrins (Pellegatta et al., 2013). In other cell types, interaction with proteins of the extracellular matrix (ECM), including LN, can lead to activation of integrins at sites called nascent adhesions (NAs) (Olsen

Received May 1, 2014; revised July 28, 2014; accepted Aug. 28, 2014.

Author contributions: M.G. and P.J.B. designed research; M.G. performed research; M.G. and P.J.B. analyzed data; M.G. and P.J.B. wrote the paper.

This study was supported by the Wellcome Trust. We thank Diane Sherman for preparing the figures; and Qiushi $\mathrm{Li}$, Heather Anderson, and Stuart Fleming for excellent technical assistance.

The authors declare no competing financial interests.

Correspondence should be addressed to Dr. Peter J. Brophy, Centre for Neuroregeneration, University of

Edinburgh, Chancellor's Building, 49 Little France Crescent, Edinburgh, EH16 4SB, United Kingdom.

E-mail: Peter.Brophy@ed.ac.uk.

DOI:10.1523/JNEUROSCI.1764-14.2014

Copyright $\odot 2014$ the authors $\quad 0270-6474 / 14 / 3413422-13 \$ 15.00 / 0$ and ffrench-Constant, 2005; Choi et al., 2008). Integrin activation leads to cell spreading, and myosin II-dependent maturation of NAs into large multiprotein signaling complexes termed focal adhesions (FAs) (Parsons et al., 2010; Wang et al., 2012). FAs are required for the formation of actomyosin-containing stress fibers, which transmit contractile forces through FAs between integrins and the ECM to consolidate cell spreading (Burridge and Chrzanowska-Wodnicka, 1996; Burridge and Wittchen, 2013). Cell spreading can regulate both proliferation and differentiation, and the level of contractile actomyosin itself can regulate differentiation (Chen et al., 1997; McBeath et al., 2004; Connelly et al., 2010).

In other cell types, FAK localizes to both NAs and FAs, and FAK promotes cell spreading at NAs partly through an inside-out mechanism (Michael et al., 2009; Serrels et al., 2010; Lawson et al., 2012; Wang et al., 2012). FAK can also promote both FA formation and turnover (Webb et al., 2004; Lim et al., 2008b). Hence, we ask here whether FAK might regulate SC proliferation and differentiation during development by controlling SC spreading and/or contractility on fragmentary BL because we have shown previously that FAK is required in vivo for SC proliferation and radial sorting (Grove et al., 2007).

Here, we show that FAK mutant SCs fail to spread on fragmentary but not mature BL in vivo. Our studies in vivo and in vitro support the hypothesis that poor spreading is responsible for reduced proliferation and premature differentiation of FAK mutant SCs during development. SC differentiation occurs at 
high cell density, putatively primed by contact-mediated $\mathrm{G}_{1}$ arrest (Morgan et al., 1991), and radial sorting has also been proposed to be triggered by high SC density (Webster, 1971; Martin and Webster, 1973). Our results suggest that low levels of contractile actomyosin rather than $\mathrm{G}_{1}$ arrest primes $\mathrm{SC}$ differentiation.

We conclude that the role of FAK is to promote SC spreading and contractility on fragmentary $\mathrm{BL}$, thus promoting proliferation and inhibiting differentiation until SCs reach a high density. Hence, we propose that FAK has a central role in coordinating SC differentiation and radial sorting during the myelination of peripheral nerves.

\section{Materials and Methods}

Animals and genotyping. All animal work conformed to United Kingdom legislation (Scientific Procedures) Act 1986 and the Edinburgh University Ethical Review policy. All mice were of either sex and were on the C57BL/6 background. Generation of mice carrying targeted loxP sites in the FAK gene, of mice bearing ablated $227 K i p 1$ genes, and the genotyping of these mice, has been previously described (Fero et al., 1996; McLean et al., 2004). Targeted ablation of FAK in embryonic Schwann cells was by crossing $F A K^{f l / f l}$ mice with mice heterozygous for both the floxed allele and Cre inserted into the CNP locus, as described previously (McLean et al., 2004; Grove et al., 2007); recombination after sciatic nerve crush was by crossing $F A K^{f l f l}$ mice with mice heterozygous for the floxed allele and transgenic for the inducible Cre recombinase Cre-ERT2 under the control of the PLP promoter followed by tamoxifen injection (Pereira et al., 2009). In both cases, control mice were either $F A K^{f l / f l}$ or $F A K^{f l /+}$. Routine genotyping was by ear biopsy using primers for FAK and CNP-CRE (Grove et al., 2007), PLP-CRE (Pereira et al., 2009), and p27Kip 1 (Fero et al., 1996). For genomic PCR, the epineurium and perineurium of sciatic nerves were removed before lysis.

Induction of recombination with tamoxifen. Tamoxifen (Sigma), dissolved in a 10:1 mixture of sunflower oil:ethanol at $10 \mathrm{mg} / \mathrm{ml}$ by shaking for $30 \mathrm{~min}$ at $37^{\circ} \mathrm{C}$, was injected into 6-week-old mice intraperitoneally at $0.2 \mathrm{mg} / \mathrm{g}$ body weight/d for $5 \mathrm{~d}$, repeated after a 1 week of recovery. Control mice were treated identically.

Sciatic nerve crush injury. Sciatic nerve crush was conducted 4 months after the last tamoxifen injection, as described previously (Sherman et al., 2012b). Forceps were dipped in charcoal before crush to identify the crush site.

Morphometry. Measurements of g-ratios was as previously described (Sherman et al., 2012b). A minimum of 100 axons was counted per animal, and three animals were used per condition.

Statistical analysis. Statistical analysis was by unpaired Student's $t$ tests or one-way ANOVA (Tukey's multiple-comparison test), as indicated, using GraphPad Prism 5.0c software.

Isolation and growth of primary rat Schwann cells. Primary rat Schwann cells were isolated as described previously (Parkinson et al., 2001) with modifications. Briefly, P2 rat sciatic nerves were incubated sequentially in $1 \mathrm{mg} / \mathrm{ml}$ collagenase I (Invitrogen) followed by $1 \mathrm{mg} / \mathrm{ml}$ collagenase I with $0.2 \mathrm{mg} / \mathrm{ml}$ trypsin (Sigma) for $30 \mathrm{~min}$ each. Purified Schwann cells were negatively immunopanned using mouse anti-Thyl.1 secreted by the OX7 hybridoma cell line (Dong et al., 1997; Parkinson et al., 2001). Immunopanning for $45 \mathrm{~min}$ at $37^{\circ} \mathrm{C}$ was repeated twice more on subsequent days to achieve $>99 \%$ Schwann cell purity as judged by $S 100 \beta$ and Sox10 immunostaining. Schwann cells were grown routinely in DMEM/ 10\% FBS (Invitrogen), $10 \mathrm{ng} / \mathrm{ml}$ Neuregulin 1 (Nrg1) (R\&D Systems), and $2 \mu \mathrm{g} / \mathrm{ml}$ forskolin (Sigma), plus L-glutamine and penicillin/streptomycin, henceforth termed Schwann cell growth medium (SCGM). Cells were grown for a maximum of 2 weeks. For Y27632 treatment, Schwann cells were suspended in SCGM with or without $5 \mu \mathrm{M}$ Y27632 (Sigma) for $30 \mathrm{~min}$ at $37^{\circ} \mathrm{C}$, then seeded on coverslips in 12 well dishes. After cell attachment, $1 \mathrm{ml}$ SCGM with or without $5 \mu \mathrm{M}$ Y27632 was added to each well, and cells were incubated for the indicated periods before fixation. For BrdU incorporation, Schwann cells were grown for $19 \mathrm{~h}$ and BrdU (10 $\mu \mathrm{M}$, Sigma) was added for a further $5 \mathrm{~h}$ before fixation.

Schwann cell differentiation and quantitation. Glass coverslips ( $15 \mathrm{~mm}$, SciQuip) were cleaned using $1 \%$ Alconox, rinsed in distilled water, treated with 3\% acetic acid, rinsed, and then stored in $80 \%$ ethanol until use. Coverslips were coated with $30 \mu \mathrm{g} / \mathrm{ml}$ poly-D-lysine (Sigma) in PBS for $1 \mathrm{~h}$ at room temperature, rinsed in distilled water, and then coated with stated concentrations of laminin 111 (Sigma) overnight at $37^{\circ} \mathrm{C}$ in a humidified chamber. Schwann cells were seeded on coverslips at indicated densities in SCGM and then grown for $24 \mathrm{~h}$. To initiate differentiation, cells were washed 4 times with DMEM and then cultured in differentiation medium (DM), consisting of DMEM/2\% FBS with L-glutamine and penicillin/streptomycin, and the stated concentration of dbcAMP. After $24 \mathrm{~h}$, medium was replaced with fresh DM with or without dbcAMP, and the cells were cultured for a further $24 \mathrm{~h}$ before fixation in $4 \%$ PFA. Differentiation was assessed by immunostaining for periaxin or Krox20. Multiple images were taken from each coverslip to obtain representative images from all areas of the coverslip, and at least 100 cells/coverslip were counted. For quantitation, $\mathrm{EGFP}^{+}$cells were counted, and the percentage of EGFP ${ }^{+}$cells that expressed the protein of interest was determined. Quantitation was with Openlab software.

Retroviruses. Retroviruses were produced by transient transfection of 293T cells with the viral packaging plasmid pSV-Psi2 and the bicistronic retroviral vector MigR1. The construct encoded the appropriate experimental cDNA with EGFP protein expression driven from an internal IRES sequence (Pear et al., 1993; Pear et al., 1998). Viral supernatant was collected $48 \mathrm{~h}$ after transfection and filtered at $45 \mu \mathrm{m} . \operatorname{Nrg} 1(10 \mathrm{ng} / \mathrm{ml})$, forskolin ( $2 \mu \mathrm{g} / \mathrm{ml}$ ), and polybrene (hexadimethrine bromide, Sigma) (4 $\mu \mathrm{g} / \mathrm{ml})$ were added to the filtrate before incubation with primary rat Schwann cells growing at 50\% confluence. After $6 \mathrm{~h}, 2$ volumes of fresh SCGM was added. After overnight incubation, the supernatant was replaced with fresh SCGM, and cells were grown for a further $48 \mathrm{~h}$ before FACS sorting. cDNA encoding FAK-related nonkinase (FRNK) were obtained from Margaret Frame (University of Edinburgh). cDNAs encoding p27Kip1, p57Kip2, and Sox2 were obtained from Addgene. pBS-FRNK was digested with EcoR1 to release the FRNK cDNA, which was cloned directly into the EcoR1 site of MigR1. pSVSport6-p57Kip1 was digested with Xho1 to release the p57Kip1 cDNA, which was directly cloned into the Xho1 site of MigR1. pCMVSport6-p27Kip1 was digested with BspE1 and Ssp1 to release the p27Kip1 cDNA. The cDNA was bluntended and cloned into MigR1 blunted at the EcoR1 site. PYX-Asc-Sox2 was digested with Not1-BglII to release the Sox 2 cDNA, which was then blunt-ended. Blunt-ended Sox 2 cDNA was cloned into MigR1 blunted at the EcoR1 site. After cloning into MigR1, expression of all cDNAs was verified by transfection in $293 \mathrm{~T}$ cells with Western blotting for the appropriate protein, and by infection of primary rat SCs followed by Western blotting and immunofluoresence.

FACS. Retrovirally infected Schwann cells were resuspended at $5 \times$ $10^{6}$ cells $/ \mathrm{ml}$ in DME-F12/2\% FBS and sorted using a BD FACSAria II cell sorter (BD Biosciences). Sorting was for EGFP, and the mean fluorescence intensity threshold was chosen for FRNK-expressing Schwann cells based on two criteria: (1) inhibition of FAK as judged by Western blots of sorted cells; and (2) replication of the spreading defect also observed in FAK mutant mouse Schwann cells (data not shown). All subsequent experiments used the same threshold so that all Schwann cell populations expressed similar levels of EGFP. Immunofluoresence was used to confirm that expression levels of EGFP corresponded to that of the exogenously expressed experimental protein (data not shown).

Western blotting, immunostaining, and microscopy. For Western blotting, the perineurium and epineurium were removed from sciatic nerves before snap freezing in liquid nitrogen and storage at $-80^{\circ} \mathrm{C}$. Sciatic nerves and primary rat Schwann cells were lysed in RIPA buffer, containing protease and phosphatase inhibitors, as described previously (Sherman et al., 2012a). For immunostaining, sciatic nerves were removed and immediately fixed with 4\% PFA for $45 \mathrm{~min}$. Conventional fluorescence microscopy, confocal microscopy (including objectives used), and electron microscopy were performed; images were collected and analyzed as previously described (Sherman et al., 2012a). All figures were prepared using Adobe Photoshop CS4 extended version 11 and were not subjected to any subsequent image processing. The method for preparation of cryosections, and immunostaining of transverse and longitudinal sections of tibial sciatic nerves, was as described previously (Grove et al., 2007). Rat Schwann cells were fixed for $20 \mathrm{~min}$ in $4 \%$ PFA before immu- 
nostaining. For BrdU immunostaining, fixed coverslips were further steam-treated for 15 min in $10 \mathrm{~mm}$ sodium citrate, $\mathrm{pH} 6.0$, as described previously (Tang et al., 2007). Primary antibodies were used at the following concentrations for immunostaining or Western blotting, as indicated: rabbit anti-FAK (Santa Cruz Biotechnology; 1:400 for Western blotting), rabbit anti-FAK pY397, anti-FAK pY577, and anti-paxillin pY118 (all Biosource; 1:1000 for Western blotting), rabbit anti-erk T202/Y204 (Cell Signaling Technology; 1:200 for Western blotting), mouse anti-vinculin (Sigma; 1:4000, immunofluorescence-streptavidin/biotin method), mouse anti-paxillin (clone 349, BD Transduction Laboratories; 1:500 for Western blotting; 1:250 for immunofluorescence), rabbit anti-myosin light chain 2 pS19 (Cell Signaling Technology; 1:50 for immunofluorescence-streptavidin/biotin method), FITC and Alexa-568 phalloidin (Invitrogen; 1:20 for fluorescence), rabbit anti-Oct6 (gift from John Bermingham, McLaughlin Research Institute; 1:100 for immunofluorescence), mouse IgG1 anti-NF-H (Sigma; 1 in 1000 for immunofluorescence), goat anti p57Kip2 (Santa Cruz Biotechnology; 1:50 for immunofluorescence), guinea pig anti Sox10 (kind gift from Michael Wegner, University of Erlangen, Bavaria, Germany); 1:1000 for immunofluorescence), rabbit anti-p27Kip1 (Santa Cruz Biotechnology; 1:100 for immunofluorescence), rabbit antiKrox20 (Covance; 1:100 for immunofluorescence), rabbit anti-Sox2 (Millipore; 1:500 for immunofluorescence), goat anti-Sox2 (Santa Cruz Biotechnology; 1:100 for immunofluorescence), rabbit anti-ErbB3 (Santa Cruz Biotechnology; 1:200 for Western blotting), mouse anti- $\beta$ actin (Sigma; 1:5000 for Western blotting), rabbit anti-Ki67 (Vector Laboratories; 1:1000 for immunofluorescence, mouse IgG1 anti-BrdU (Vector Laboratories; 1:20 for immunofluorescence), horse biotinylated antimouse (Vector Laboratories; 1:200 for immunofluorescence), donkey biotinylated antirabbit (Vector Laboratories; 1:200 for immunofluorescence), and Alexa568 streptavidin (Invitrogen; 1:1000 for immunofluorescence). All other primary and secondary antibodies and nuclear stains were as described previously (Grove et al., 2007; Sherman et al., 2012a, b).

\section{Results}

\section{Immature SCs without FAK spread poorly in vivo on} fragmentary $\mathrm{BL}$ and fail to reach the late promyelinating stage Immature murine SCs begin to form a BL soon after they differentiate from their precursors between E13.5 and E15.5 (Jessen and Mirsky, 2005); the BL has been described previously as initially fragmentary during development but intact in adults (Webster, 1971; Webster et al., 1973). Because FAK may itself influence the formation of BL in some tissues (Beggs et al., 2003), and FAK mutants have persistent radial sorting defects beginning at E17.5 (Grove et al., 2007), we first asked whether the BL appeared less intact around unsorted axon bundles in mutant compared with control sciatic nerves. We examined control and FAK mutant SCs from E17.5 to P20 and the BL around unsorted axon bundles appeared similar in mutant compared with controls indicating that FAK was not required for BL assembly (Fig. 1). At E17.5, there were large areas of naked axon interspersed with thin areas
Control
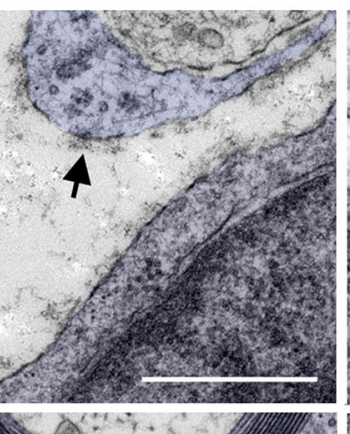
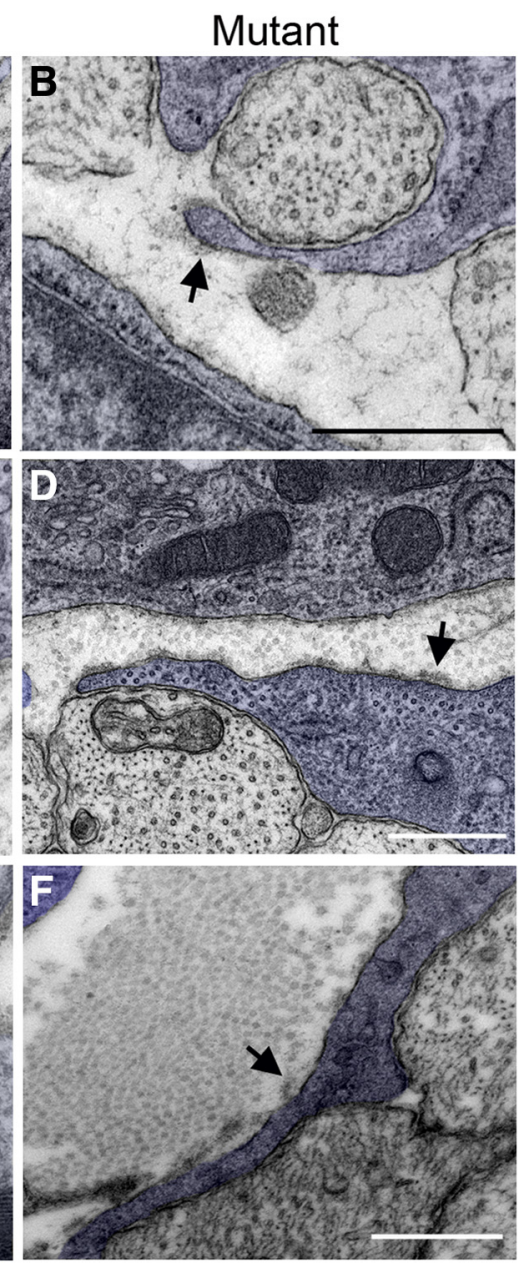

Figure 1. BL is fragmentary around both immature control and FAK mutant SCs in vivo. Electron micrographs of transverse ciatic nerve sections where SCs are pseudocolored to aid BL visualization. $A, B, A t E 17.5$, BL of control and mutant SCs surrounding and mutant, whereas it is thicker and unbroken around thinly myelating control SCS. E, F, At P2O BL of contro Scale bars, $0.5 \mu \mathrm{m}$. Genotypes: control, $F A K^{f l / f l}$ or $F A K^{f l /+}$; mutant, $F A K^{f l / f l}: C N P-C r e^{-/+}$.

of BL in both controls and mutants. Postnatally, the BL remained fragmentary around unsorted axon bundles in both controls and mutants, although myelinating SCs acquired an electron-dense unbroken BL. Hence, the integrity of the BL in both control and mutant sciatic nerves appears to depend on the developmental stage of the SC rather than the age of the mouse.

FAK regulates cell spreading (Ilić et al., 1995). Therefore, we examined whether control and FAK mutant SCs spread equally well on fragmentary BL during radial sorting in vivo. In transverse sections of control sciatic nerves at P9, axon bundles were surrounded by thin SC processes, which generally enveloped their associated axon bundle (Fig. 2Aa). This was also seen in longitudinal sections at P5 (Fig. 2Ac,e). In contrast, axon bundles in mutant sciatic nerves at P5 and P9 were associated with short stubby SCs, which failed to extend either around or along their associated bundles, thus leaving large areas of naked axon (Fig. $2 A b, d, f)$.

A small minority of FAK mutant SCs reach the promyelination stage but fail to myelinate (Grove et al., 2007). We define early promyelinating SCs as those that have formed 1:1 relationships with axons but have not yet begun the process of forming multiple cytoplasmic wraps around the associated axon. We ex- 
A

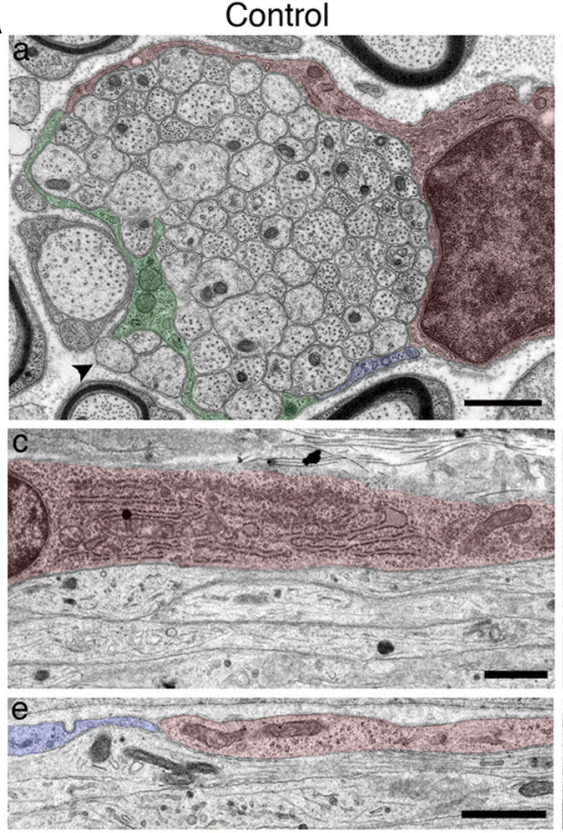

B

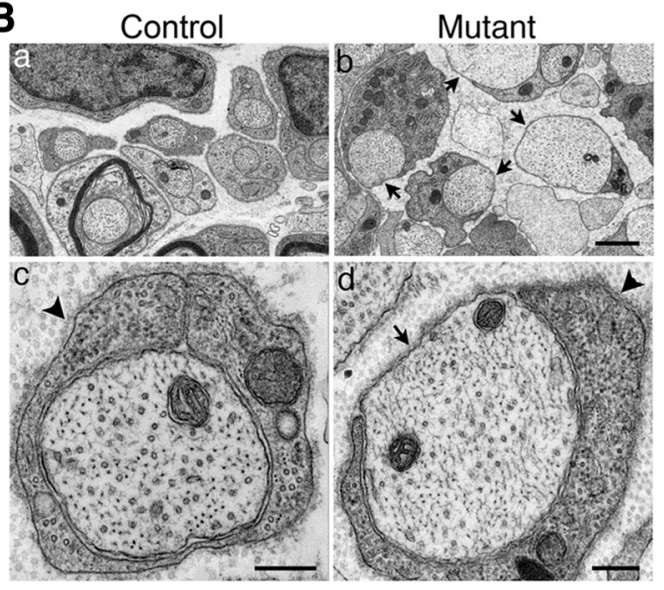

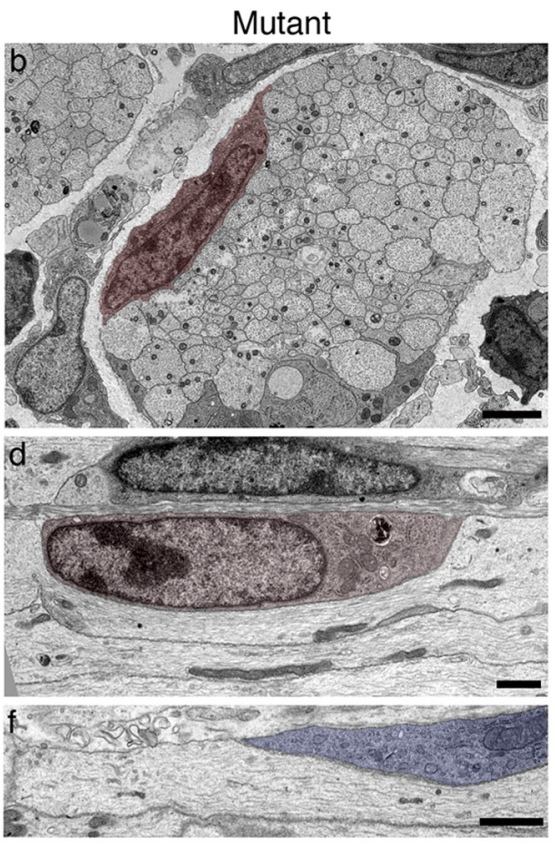

C

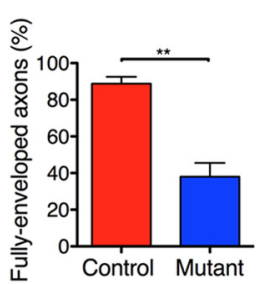

Figure 2. Spreading of FAK mutant SCs is impaired in vivo. $A$, Electron micrographs of postnatal sciatic nerves where $S C s$ are pseudocolored to aid visualization. Transverse $(\boldsymbol{a}, \boldsymbol{b})$ and longitudinal $(\boldsymbol{c}-\boldsymbol{f})$ sections at $\mathrm{P9}$ and $\mathrm{P} 5$, respectively, show immature SCs associated with unsorted axon bundles. Control SCs extend processes along axon bundles in both transverse $(\boldsymbol{a})$ and longitudinal $(\boldsymbol{c}$, $\boldsymbol{e})$ directions. Tips of adjacent $S($ processes closely abut $(\boldsymbol{a}, \boldsymbol{e})$, although some regions of naked axon are observed (a, arrowhead). In contrast, mutant $S(s$ are short and stubby and extend poorly in both transverse $(\boldsymbol{b})$ and longitudinal $(\boldsymbol{d}, \boldsymbol{f})$ directions; extensive regions of naked axon are observed $(\boldsymbol{b}, \boldsymbol{d}, \boldsymbol{f})$. Scale bars, $\boldsymbol{A} \boldsymbol{a}, \boldsymbol{c}-\boldsymbol{f}, 1 \mu \mathrm{m} ; \boldsymbol{A} \boldsymbol{b}, 2 \mu \mathrm{m}$. $\boldsymbol{B}$, Electron micrographs of transverse sections of early promyelinating SCs associated with single axons at $\mathrm{P} 5$. Ba, Control SCs fully envelop their associated axons, with no naked axon between the SC processes. $\boldsymbol{B} \boldsymbol{b}$, Mutant SCS fail to envelop their associated axons, leaving extensive regions of naked axon (arrows). $\boldsymbol{B} \boldsymbol{c}, \boldsymbol{d}$, Control and mutant SCs have immature fragmentary BL (arrowhead). Regions of naked axon in mutants are associated with BL (arrow), suggesting withdrawal of SC processes. Scale bars: $\boldsymbol{B} \boldsymbol{a}, \boldsymbol{b}, 1 \mu \mathrm{m} ; \boldsymbol{B C}, \boldsymbol{d}, 0.25 \mu \mathrm{m}$. $\boldsymbol{C}$, At P5, the percentage of sorted axons that were fully enveloped was significantly greater in control compared with mutant sciatic nerves. Values are mean $\pm \mathrm{SEM} ; n=2 .{ }^{* *} p=0.0063$ (unpaired Student's $t$ test). Genotypes: control, $F A K^{A / f l}$ or $F A K^{A / /+}$; mutant, FAK ${ }^{H / f I}:$ CNP-Cre $^{-1+}$.

amined early promyelinating SCs at P5 and found that both control and mutants SCs were surrounded by a fragmentary BL (Fig. $2 B c, d)$. However, only $38 \%$ of FAK mutant early promyelinating SCs completely surrounded their associated axon compared with $89 \%$ of controls (Fig. $2 B a-d, C$ ). Areas of naked axon were associated with redundant BL (Fig. $2 B d$; and data not shown), suggesting that SC processes had withdrawn, although the paucity of such profiles in controls suggests that this is normally a transitory event (Fig. 2C). Hence, both control and mutant early promyelinating SCs are surrounded by a fragmentary BL, but control SCs stably extend along the $\mathrm{BL}$ and proceed to myelinate, whereas FAK mutant SCs do not.

\section{SCs initiate differentiation prematurely in vivo without FAK}

Reduced cell spreading can both inhibit proliferation and prime cells for differentiation, thus conferring a greater sensitivity to inducers of differentiation (Chen et al., 1997; McBeath et al., 2004; Connelly et al., 2010; Théry, 2010). We have previously shown that proliferation of FAK mutant immature SCs is reduced in vivo (Grove et al., 2007); therefore, we hypothesized that these poorly spread cells might be primed for differentiation. If this were so, they would initiate differentiation prematurely compared with controls in vivo. Hence, we examined the expression of nuclear markers of early SC differentiation.

We examined expression of the cyclindependent kinase inhibitors p27Kip1 and p57Kip2, which are reported to, respectively, promote and inhibit SC differentiation in vitro (Heinen et al., 2008; Li et al., 2011); further, the accumulation of both proteins may be inhibited by FAK (Bryant et al., 2006; Lim et al., 2008a). We also examined the expression of the transcription factors Oct6 and Krox20. Oct6 is transiently induced in immature SCs and peaks shortly after birth, whereas Krox20 is induced embryonically and remains elevated in myelinating SCs (Blanchard et al., 1996; Topilko et al., 1997; Parkinson et al., 2003). We examined the nuclear expression of p57Kip2, p27Kip1, Oct6, and Krox20 during development at two time points that were chosen such that the expression of each marker in control SCs was higher at the later time point. Hence, increased expression of a marker in mutant SCs at the earlier time point would indicate premature upregulation, rather than delayed downregulation.

The expression of p57Kip2 in control SC nuclei was very low at E17.5 (data not shown) but increased between E18.5 and $\mathrm{P} 1$ (Fig. $3 A, B$ ), suggesting that $\mathrm{p} 57 \mathrm{Kip} 2$ is indeed a marker of immature SC differentiation. Mutant SCs expressed significantly more nuclear p57Kip2 at both ages, indicating that $\mathrm{p} 57 \mathrm{Kip} 2$ is prematurely upregulated in mutant SCs in vivo (Fig. $3 A, B$ ). p27Kip1 was first detected at E18.5 in control SC nuclei, and expression increased between E18.5 and P5 (Fig. 3C,D), suggesting that p27Kip1 is a further marker of immature SC differentiation. In mutant sciatic nerves, p27Kip1 was also prematurely upregulated at E18.5 (Fig. 3C,D).

In control sciatic nerves, the number of Oct6 ${ }^{+}$nuclei increased by almost threefold between E17.5 and E18.5 (Fig. 3 E, F) and continued to increase up to P1 (data not shown), consistent with the findings of others (Blanchard et al., 1996). Oct6 was 
prematurely upregulated in mutant SCs at both E17.5 and E18.5 (Fig. 3E,F). Likewise, Krox20 expression was significantly greater in mutant versus control SC nuclei at E18.5. However, whereas Krox $20^{+}$SC nuclei continued to increase in number in control SCs postnatally, Krox20 declined in mutant SCs (Fig. 3G,H). This indicated that, although mutant Schwann cells initiated differentiation prematurely, the decline in Krox20 expression was consistent with the fact that these cells do not go on to myelinate.

In summary, each of these nuclear markers of early SC differentiation was prematurely upregulated in FAK mutant nerves. This supports the hypothesis that immature FAK mutant SCs are prematurely primed for differentiation and thus are hypersensitive to differentiation signals, most likely cAMP.

FAK regulates $\mathrm{SC}$ spreading and is required for proliferation on low concentrations of $\mathrm{LN}$ in vitro

To investigate the possible role for a spreading defect in regulating the proliferation and differentiation of FAK mutant SCs in vivo, we turned to an in vitro model. Initial experiments were conducted with mouse SCs, but for technical reasons (see below), we turned to rat SCs, which gave similar results. FAK was functionally inactivated in primary rat SCs by coexpression of FRNK, the dominant negative inhibitor of FAK (Richardson and Parsons, 1996; Pear et al., 1998).

Purified primary rat SCs were infected with the bicistronic MigR1 retrovirus expressing either EGFP (control SCs) or EGFP coexpressed with FRNK (FRNK SCs). FRNK SCs displayed down-regulation of tyrosine phosphorylation of FAK targets consistent with effective inhibition of endogenous FAK activity (Fig. 4A).

Because FAK interacts with LNbinding integrins in SCs (Chernousov et al., 2007), and LN-dependent proliferation of SCs in vivo increases as the BL develops between E15.5 and E17.5 (Yu et al., 2005), we asked how control and FRNK SCs responded to increasing levels of $\mathrm{LN}$ in vitro. Control SCs seeded on coverslips coated with $0.2 \mu \mathrm{g} / \mathrm{ml}$ or $5.0 \mu \mathrm{g} / \mathrm{ml} \mathrm{LN}$ (low and high LN, respectively) flattened, spread, and polarized longitudinally within $2 \mathrm{~h}$ (Fig. 4B). After $24 \mathrm{~h}$, these cells were extensively spread and polarized on both substrates (Fig. 4B). In contrast, FRNK SCs failed to flatten or spread on low LN (Fig. 4B) but eventually spread and polarized after 24 h on high LN (Fig. 4B).

These data show that the requirement for FAK in promoting SC spreading is much more pronounced at low levels of LN.
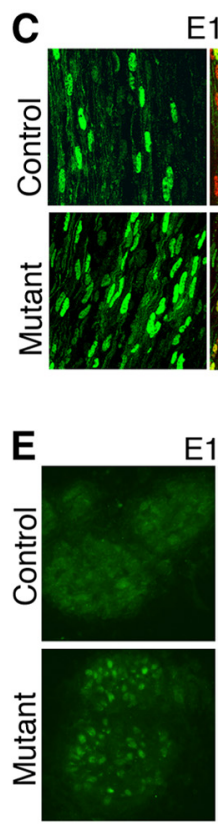
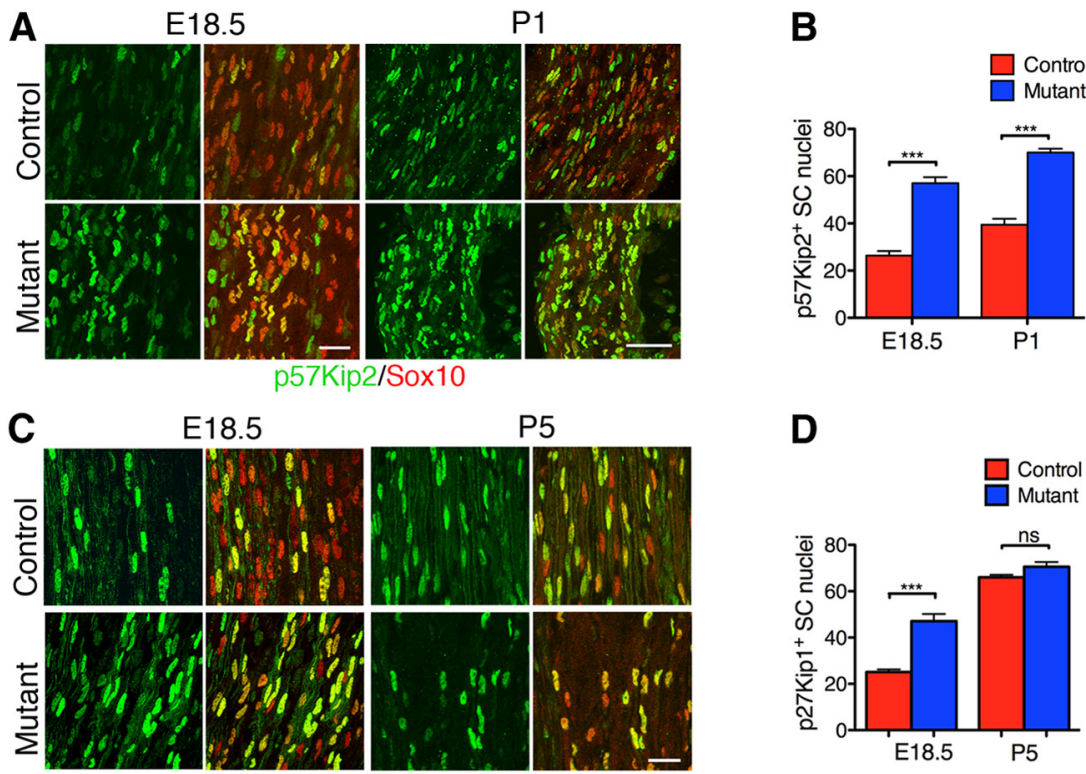

P5

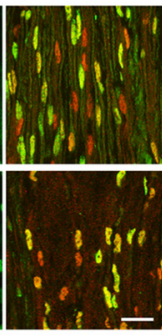

p27Kip1/Sox10

E17.5

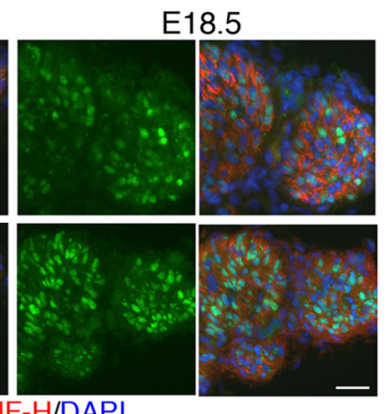

$\mathbf{F}$
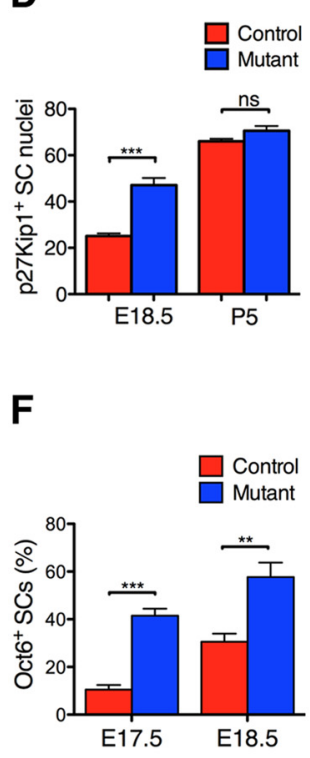

G

E18.5

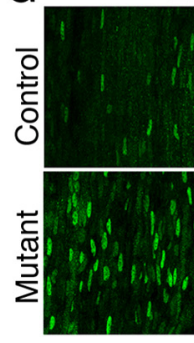

P21

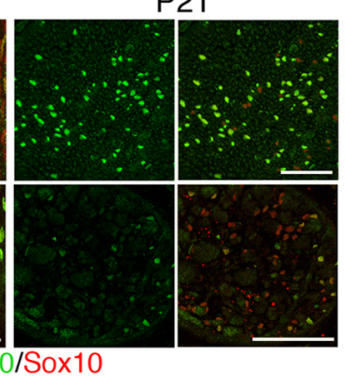

H

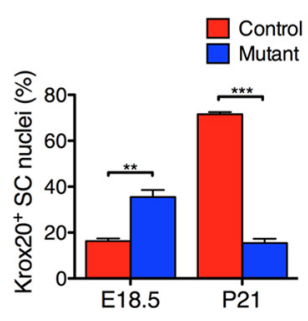

Figure 3. FAK mutant SCs initiate differentiation prematurely in vivo. Expression of nuclear markers of $\mathrm{SC}$ differentiation in transverse and longitudinal sciatic nerve sections from control and mutant mice. The sciatic nerve was delineated by immunostaining for neurofilament $(\mathrm{NF}-\mathrm{H})(\boldsymbol{E})$, or SCs wereidentified using the nuclear marker $\operatorname{Sox} 10(A, C, G) . A, B$, Longitudinal sections of sciatic nerves at E18.5 and P1. p57Kip2 is prematurely upregulated in mutant SCs at E18.5 and remains elevated compared with control at P1. Values are mean \pm SEM; $n=3,3$ sections per sciatic nerve. ${ }^{* * *} p=0.0007$, E18.5 (unpaired Student's $t$ test). ${ }^{* * *} p=0.0005, P 1$ (unpaired Student's t test). C, D, Longitudinal sections of sciatic nerves at E18.5 and P5. p27Kip1 is prematurely upregulated at E18.5 in mutant SCS, but at P5 levels are not significantly different from control. Values are mean \pm SEM; $n=3,3$ sections per sciatic nerve. ${ }^{* * *} p=0.0026$, E18.5 (unpaired Student's $t$ test). ns, Not significant. $E, F$, Transverse sections at $E 17.5$ and $E 18.5 .0 c t 6$ is prematurely upregulated at $E 17.5$ in mutant $S($ s and remains elevated compared with control at E18.5. Values are mean $\pm \mathrm{SEM} ; n=3,3$ sections per sciatic nerve. ${ }^{* * *} p=0.0009$, E17.5 (unpaired Student's $t$ test). ${ }^{* *} p=0.0079$, E18.5 (unpaired Student's $t$ test). G, $\boldsymbol{H}$, Longitudinal and transverse sections at at E18.5 and P21, respectively. Krox20 is prematurely upregulated in mutant $\mathrm{SCS}$ at E18.5, but at $\mathrm{P} 21 \mathrm{Krox} 20$ is substantially decreased compared with control SCS. Values are mean $\pm \mathrm{SEM} ; n=3$ (E18.5) or 2 (P21), 3 sections per sciatic nerve. ${ }^{* *} p=0.0038$, E18.5 (unpaired Student's $t$ test). ${ }^{* * *} p=$

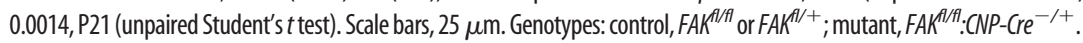

Further, it suggests that the poor spreading of immature FAK mutant SCs in vivo could be due to low levels and/or the availability of LN in fragmentary BL. Hence, we used FRNK SCs grown on low or high LN in vitro to model the response of FAK mutant SCs to fragmentary BL or more mature BL, respectively. 


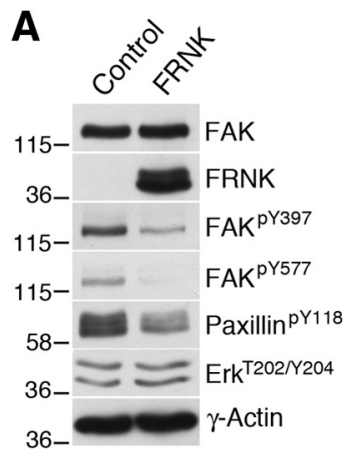

B

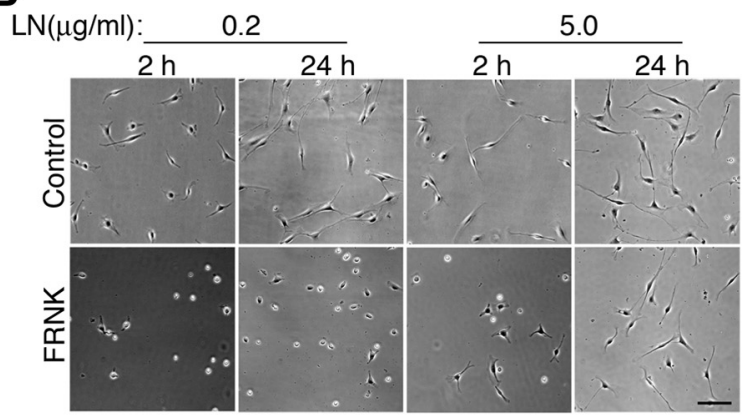

\section{C}

$\mathrm{LN}(\mu \mathrm{g} / \mathrm{ml})$ :

Y27632:

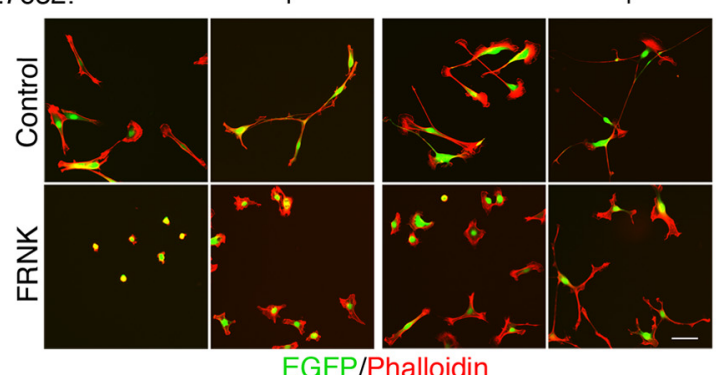

D

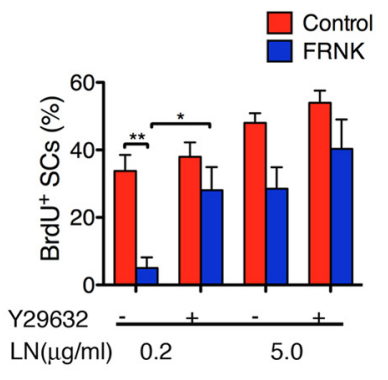

Figure 4. Spreading and proliferation of SCS without functional FAK in vitro are regulated by $L N$ concentration. Primary rat SCS expressed either EGFP (Control) or EGFP + FRNK (FRNK). $A$, Western blot showing that FRNK blocks endogenous FAK activity in SCs as measured by reduced phosphorylation of FAK at $Y^{397}$ (autophosphorylation) and $Y^{577}$ (trans-phosphorylation by Src family tyrosine kinases) and the FAK target paxillin at $Y^{118}$. The potential FAK target Erk remains unaffected. Molecular masses are shown in kilodaltons. B, Phase-contrast images of control and FRNKSCs seeded on low $(0.2 \mu \mathrm{g} / \mathrm{ml})$ or high $(5.0 \mu \mathrm{g} / \mathrm{ml}) \mathrm{LN}$ for 2 and $24 \mathrm{~h}$. Spreading and polarization of control SCS are complete by $24 \mathrm{~h}$ on both low and high LN. In contrast, FRNK SCS fail to spread or polarize on low LN by $24 \mathrm{~h}$. On high LN, FRNK SCs spread but are generally unpolarized after $2 \mathrm{~h}$; but by $24 \mathrm{~h}$, they are spread and polarized, although less extended than control SCs. Scale bar, $100 \mu \mathrm{m}$. C, SCs were cultured for $24 \mathrm{~h}$ in the absence ( - ) or presence $(+)$ of ROCK inhibitor Y27632 (5 $\mu \mathrm{M})$. Fixed cells were incubated with rhodamine phalloidin (red) to visualize the F-actin cytoskeleton and cell shape. All SCS, except FRNK SCS on low LN, were polarized, and extended long thin processes in the presence of Y27632. FRNKSCs on low LN spread more in the presence of Y27632, although they remained round and unpolarized. Scale bar, 50 $\mu \mathrm{m}$. D, Proliferation of SCs cultured for $24 \mathrm{~h}$ was measured by incubation with BrdU $(10 \mu \mathrm{m})$ for the final $5 \mathrm{~h}$. Control SCs proliferated significantly better than FRNK SCs on low LN, but Y27632 treatment normalized the proliferation of FRNKSCs. On high LN, proliferation of control and FRNK SCS was not significantly different. Values are mean \pm SEM; $n=3,2$ coverslips per experiment. ${ }^{*} p=0.0223$ (unpaired Student's $t$ test). ${ }^{* *} p=0.0024$ (unpaired Student's $t$ test).

Because reduced cell spreading can lead to $\mathrm{G}_{1}$ arrest (Chen et al., 1997), we asked whether the proliferation of FRNK SCs on low LN was compromised, as we have found previously for FAK mutant SCs in vivo (Grove et al., 2007). On low LN, BrdU incorporation by control SCs was indeed much greater than for FRNK SCs; however, proliferation of control and FRNK SCs on high LN was not significantly different (Fig. 4D).

To explore the relationship between spreading and proliferation further, we asked whether we could stimulate the proliferation of FRNK SCs on low LN by improving their ability to spread. FAK regulates RhoA activity (Schaller, 2010), and it has been shown in SCs mutant for integrin-linked kinase that inhibition of the RhoA effector ROCK with Y27632 restores their ability to extend on LN (Pereira et al., 2009). Y27632 promoted the spreading or extension of both control and FRNK SCs, thus also confirming that RhoA was active (Fig. 4C). Control SCs on low or high LN and FRNK SCs on high LN extended long thin processes, whereas FRNK SCs on low LN responded by spreading but did not polarize (Fig. 4C). The increased spreading of FRNK SCs on low LN caused by Y27632 was associated with a 5.6-fold increase in proliferation, whereas Y27632 did not significantly stimulate the proliferation of control SCs on either low or high LN or of
FRNK SCs on high LN (Fig. 4D). These results suggest that the reduced proliferation of SCs lacking functional FAK on low $\mathrm{LN}$ in vitro is a consequence of defective spreading and that a similar mechanism may underlie the reduced proliferation of poorly spread FAK mutant SCs in vivo. Mouse FAK-null Schwann cells spread and proliferated similarly to rat Schwann cells expressing FRNK (data not shown). Subsequent differentiation experiments required large numbers of SCs, which were grown on poly-D-lysine before experiments. However mouse FAK mutant and FRNK SCs proliferated very poorly on poly-D-lysine, as they do on low LN. This issue was solved using rat SCs. Large numbers of rat SCs were grown before infection with FRNK retrovirus and FACS sorting. Rat SCs could also be purified $(>99 \%)$ more readily than mouse SCs, thus eliminating any potential effects of contaminating fibroblasts.

\section{SCs lacking functional FAK are primed for differentiation by poor spreading on low $\mathrm{LN}$ in vitro}

FAK mutant Schwann cells spread poorly and express differentiation markers prematurely in vivo. Hence, we asked whether poor spreading on low LN in vitro primed FRNK SCs for differentiation. However, FRNK SCs on low LN also display reduced proliferation (Fig. 4D), which corresponds to a longer $G_{1}$ phase of the cell cycle (Zetterberg and Larsson, 1985). Because cell differentiation occurs in $\mathrm{G}_{1}$ (Mummery et al., 1987; Dalton, 2013), it was necessary first to discriminate the role of $G_{1}$ cell-cycle status from that of cell spreading in the regulation of differentiation. Hence, we first compared cell size and $\mathrm{G}_{1}$ status of control and FRNK SCs with SCs overexpressing p27Kip1 because p27Kip1 overexpression is reported to arrest the cell-cycle in $G_{1}$ (Toyoshima and Hunter, 1994).

$\mathrm{G}_{1}$ status was measured in SCs plated at low density by immunostaining for Ki67, which is expressed throughout the cell cycle with the exception of early $G_{1}$ (Kreipe et al., 1993). There was similar expression of Ki67 in control SCs on low LN (38.5\%) and high LN (41.6\%). However, although FRNK SCs had similar levels of Ki67 to control cells on high LN (43.9\%), only $11.4 \%$ of FRNK SCs were $\mathrm{Ki}^{+} 7^{+}$on low LN showing that $>88 \%$ are in $\mathrm{G}_{1}$. As predicted, $100 \%$ of SCs overexpressing p $27 \mathrm{Kip} 1$ were in $\mathrm{G}_{1}$ on both low and high LN (Fig. 5A). FRNK SCs spread on high but not low LN, whereas control and p27Kip1 SCs spread well on both low and high LN (Figs. $4 B, C$ and $6 B$ ). Thus, by comparing p27Kip1-overexpressing SCs with FRNK SCs, we could discriminate between the effects of $G_{1}$ arrest and cell spreading on SC differentiation.

To investigate their propensity for differentiation, control, FRNK-, or p27Kip1-overexpressing SCs were seeded on low and high LN at a range of densities, treated for $48 \mathrm{~h}$ with dbcAMP (200 
$\mu \mathrm{M})$ and then immunostained for the differentiation marker periaxin. Negligible differentiation occurred in the absence of dbcAMP (data not shown). On low LN and at low cell density, only $9.2 \%$ of control SCs differentiated, comparable with p27Kip1-overexpressing SCs, despite the fact that the latter were arrested in $\mathrm{G}_{1}$ (Fig. $5 B, C)$. Differentiation of both control and p27Kip1-overexpressing SCs increased with cell density and was significantly greater at high compared with low cell density (Fig. $5 B, C$ ). In marked contrast, 79.9\% of FRNK SCs on low LN differentiated at low cell density; further, these SCs differentiated equally well at all densities and were comparable to p27Kip1-overexpressing SCs at high density (Fig. $5 B, C$ ). Hence, FRNK SCs on low LN were primed for differentiation at all densities, whereas control and p27Kip1 overexpressors were only primed at high density.

Control and p27Kip1-overexpressing SCs differentiated more as cell density increased on low and high LN (Fig. 5B,C). However, and in contrast to their behavior on low LN, FRNK SCs on high LN also differentiated as a function of cell density similar to control and p27Kip1-overexpressing SCs (Fig. $5 B, C$ ). Hence, on high LN, FRNK SCs were only primed to differentiate at high density.

In summary, differentiation of control SCs on low and high LN was as would have been predicted from previous work (Morgan et al., 1991): namely, little differentiation at low cell density but greatly increased differentiation at high density. However, p27Kip1-overexpressing SCs behaved similarly to control SCs, showing that differentiation is largely independent of $\mathrm{G}_{1}$ cell-cycle status. Furthermore, these data suggest that, on low LN, FAK is required to make SC differentiation sensitive to cell density. The fact that poorly spread FRNK SCs at low density on low LN are primed for differentiation, in contrast to well-spread control and p27Kip1-overexpressing SCs, suggests that it is the spreading defect of FAK mutant SCs on fragmentary BL in vivo that primes them for premature differentiation.

\section{FAK is required for SC contractility on low $\mathrm{LN}$ in vitro and} contractility may regulate SC differentiation

We next investigated potential mechanisms that might explain why poorly spread FRNK SCs on low LN at low density are hypersensitive to the induction of differentiation by dbcAMP.

Reduced cell spreading is associated with low levels of contractile actomyosin ("contractility") and an increased cellular F/G actin ratio, both of which can prime cells for differentiation (McBeath et al., 2004; Connelly et al., 2010; Théry, 2010). Contractility in spreading/ migrating cells is mediated by stress fibers exerting tension through focal adhesions (Burridge and Chrzanowska-Wodnicka, 1996; Bur-
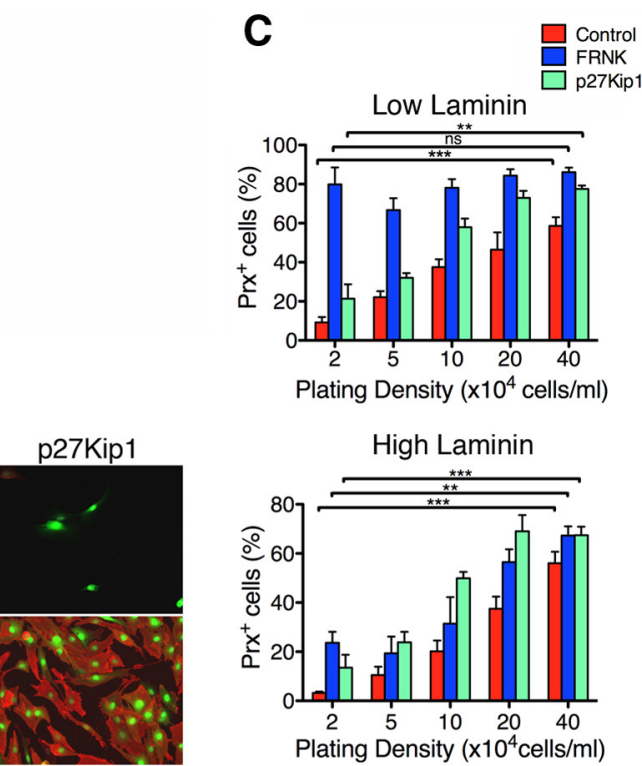

Plating Density $\left(\times 10^{4}\right.$ cells $\left./ \mathrm{ml}\right)$

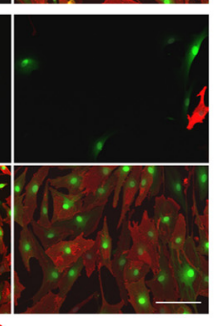

EGFP/periaxin

Figure 5. SC differentiation is regulated by density, independently of cell-cycle status. Primary rat SCs expressed EGFP (Control), EGFP + FRNK (FRNK), or EGFP + p27Kip1 (p27Kip1). A, SCs were grown for $24 \mathrm{~h}$ on low $(0.2 \mu \mathrm{g} / \mathrm{ml})$ or high $(5 \mu \mathrm{g} / \mathrm{ml}) \mathrm{LN}$ and

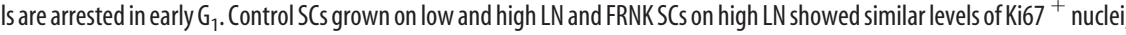
作

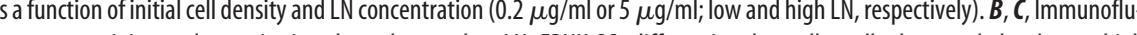

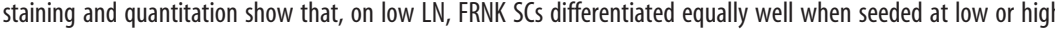
SCs $2 \times 10^{4} / \mathrm{ml}$ compared with $40 \times 10^{4} / \mathrm{ml}$ (unpaired Student's t test). ${ }^{* *} p=0.0050$, FRNK SCs $2 \times 10^{4} / \mathrm{ml}$ compared with $40 \times 10^{4} / \mathrm{ml}$ (unpaired Student's $t$ test). ${ }^{* * *} p=0.0010 \mathrm{p} 27 \mathrm{Kip} 1 \mathrm{SCs} 2 \times 10^{4} / \mathrm{ml} \mathrm{compared} \mathrm{with} 40 \times 10^{4} / \mathrm{ml}$ (unpaired Student's $t$ test). Scale bar, $100 \mu \mathrm{m}$.

ridge and Wittchen, 2013), and by myosin II-mediated retrograde flow of actin at the lamellipodium-lamellum interface where actomyosin arcs (precursors to stress fibers) form (Parsons et al., 2010; Burridge and Wittchen, 2013). In addition to myosin II activity, formation of these contractile actomyosin structures requires FAs and actin polymerization in lamellipodia (Giannone et al., 2007; Choi et al., 2008; Parsons et al., 2010; Burridge and Wittchen, 2013). Hence, we examined F-actin and FAs in FRNK-, control-, and p27Kip1-overexpressing SCs because FAK can promote cell spreading (Ilić et al., 1995; Tamura et al., 1998; Hsia et al., 2003; Serrels et al., 2010), actin polymerization in lamellipodia (Serrels et al., 2007), and the formation and turnover of FAs (Tamura et al., 1998; Webb et al., 2004; Michael et al., 2009; Pasapera et al., 2010; Lawson et al., 2012).

Phalloidin staining revealed that control SCs contained prominent lamellipodia and stress fibers/arcs on both low and high LN. FRNK SCs also formed lamellipodia and stress fibers/arcs on high 
A

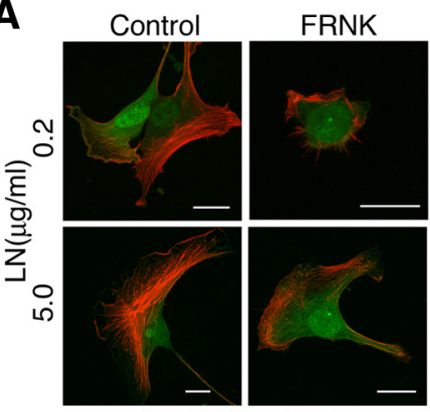

EGFP/Phalloidin

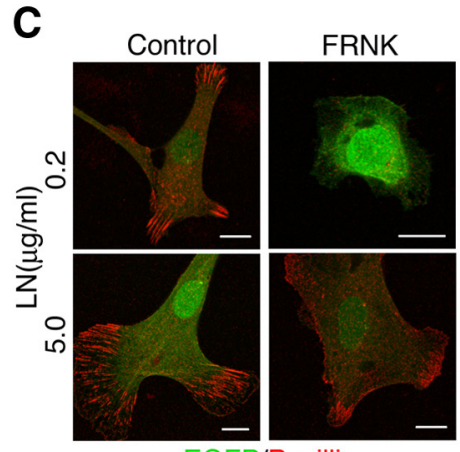

EGFP/Paxillin
B
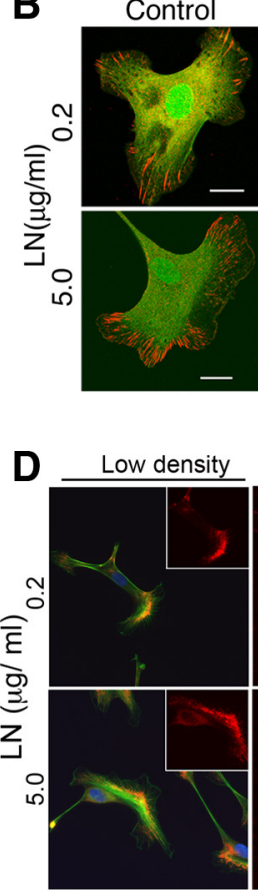

FRNK

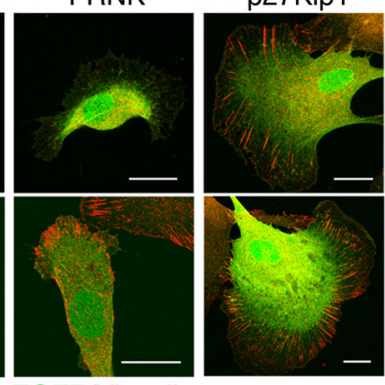

EGFP/Vinculin

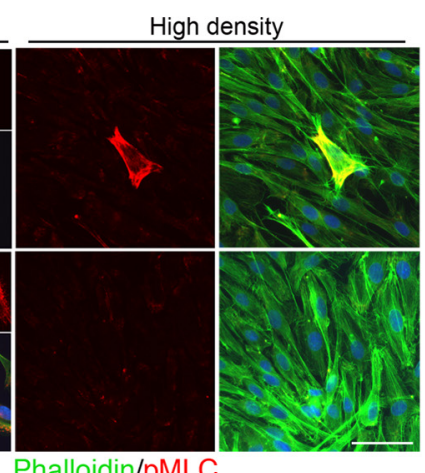

Figure 6. FAK activity is required for $\mathrm{SC}$ contractilty on low $\mathrm{LN}$ at low cell density, and control $\mathrm{SC}$ contractility is reduced at high density. A-C, Primary rat SCs expressing exogenous EGFP (Control), EGFP + FRNK (FRNK), or EGFP + p27Kip1 (p27Kip1) were grown at low cell density $\left(2 \times 10^{4}\right.$ cells/ml) on low or high LN. $A$, The F-actin cytoskeleton of SCs grown for $24 \mathrm{~h}$ was visualized with rhodamine phalloidin (red). Control SCs on low or high LN have prominent stress fibers arcs and lamellipodia, whereas FRNKexpressing SCs have stress fibers/arcs and lamellipodia on high but not low LN. Scale bars, $15 \mu \mathrm{m}$. B, C, Immunostaining for vinculin and paxillin to detect FAs. $\boldsymbol{B}$, Control and p27Kip1-overexpressing SCs have prominent vinculin-positive FAs on low and high LN. On high LN, FRNK SCs have peripheral vinculin-positive FAs. On low LN, FRNK SCs lack vinculin-positive FAs. Scale bars, 15 $\mu \mathrm{m}$. C, Control SCs contain prominent paxillin-positive FAs on low and high LN. FRNKSCs contain large peripheral paxillin-positive FAs on high LN, but not on low LN. Scale bars, $10 \mu \mathrm{m} . \boldsymbol{D}$, Control SCs were seeded at $2 \times 10^{4} / \mathrm{ml}$ (low density) or $4 \times 10^{5} / \mathrm{ml}$ (high density) on low or high LN, then grown for $24 \mathrm{~h}$ before immunostaining for pMLC to detect active myosin II (red) and phalloidin staining to detect F-actin (green). SCs at low cell density have intense PMLC staining, whereas at high density immunostaining is much reduced, regardless of $L N$ amount. Note the difference in $\mathrm{pMLC}$ levels between Schwann cells and the lone contaminating fibroblast in the high density culture. Phalloidin staining shows that, on low and high LN, prominent stress fibers observed at low SC density are reduced at high $\mathrm{SC}$ density, whereas cortical F-actin staining remains. Insets, pMLC immunostaining at low cell density. Scale bar, $100 \mu \mathrm{m}$.

LN (Fig. 6A). In contrast, FRNK SCs on low LN failed to form either lamellipodia or stress fibers/arcs (Fig. 6A). Hence, contractile F-actin was reduced in FRNK SCs on low LN.

Contractile F-actin in spreading/migrating cells depends on FAs, and FAK can regulate FA formation and turnover; therefore, we immunostained for vinculin to determine whether there were mature FAs (Ziegler et al., 2008). No difference in vinculin-labeled FAs was seen between control and p27Kip1overexpressing SCs on either low or high LN, showing that in SCs p27Kip1 does not inhibit FA formation even though it is reported to do so in other cell types (Besson et al., 2004) (Fig. 6B). FRNK SCs contained large peripheral vinculin-positive FAs on high LN (Fig. $6 B$ ), which is consistent with the results of others, where cells on high concentrations of ECM required FAK for FA turnover (Ilić et al., 1995; Richardson et al., 1997; Webb et al., 2004). However, FRNK SCs failed to form vinculin-containing FAs on low LN (Fig. 6B). To exclude the possibility that FAs still form when FAK is inhibited on low LN, but that they simply lack vinculin (Pasapera et al., 2010), we also immunostained for paxillin because this protein localizes to both NAs and mature FAs independently of FAK (Lawson and Schlaepfer, 2012; Lawson et al., 2012). The results for paxillin localization paralleled those for

vinculin (Fig. 6C). The number of FRNK SCs with FAs as detected by vinculin staining as a percentage of control SCs was $4.6 \pm 2.3$ and $96.3 \pm 3.7$ on low and high $\mathrm{LN}$, respectively (mean $\pm \mathrm{SEM} ; n=3, p=$ 0.003 , paired Student's $t$ test). Essentially, $100 \%$ of all control SCs and p27Kip1overexpressing SCs had vinculin-positive FAs.

Because FRNK SCs on low LN fail to form lamellipodia, stress fibers/arcs, or FAs, it appears that they are not contractile. Hence, priming of low-density FRNK SCs for differentiation on low LN is associated with low levels of contractile actomyosin, whereas resistance of control and p27Kip1-overexpressing SCs to differentiation at low density is associated with high contractility. Therefore, we asked whether the priming of control SCs for differentiation at high density was also associated with reduced levels of contractile actomyosin. Myosin II activity is necessary (but not sufficient; see Discussion) for contractility and can be assessed by immunostaining for phosphorylation of its regulatory light chain on Serine19 (pMLC) (Vicente-Manzanares et al., 2009).

Control SCs seeded at low and high density and on either low or high LN were immunostained for pMLC and costained with phalloidin to visualize F-actin. At low SC density, prominent F-actin stress fibers/arcs and intense pMLC were observed (Fig. 6D). However, at high density, stress fibers/arcs were reduced (although cortical F-actin staining remained prominent), and pMLC was markedly reduced (Fig. 6D). Hence, similarly to FRNK SCs on low $\mathrm{LN}$, priming of control SCs for differentiation at high density is associated with reduced actomyosin contractility. Interestingly, FRNK SCs on low LN have normal levels of pMLC (data not shown), suggesting that different mechanisms control the reduced contractility of FRNK SCs on low LN and control SCs at high density (see Discussion).

\section{p27Kip1 and p57Kip2 neither prime nor inhibit \\ SC differentiation}

Our data suggest that FAK mutant SCs spread poorly on fragmentary BL in vivo and are thus primed for and initiate premature differentiation even though they do not go on to myelinate. FAK may negatively regulate the levels of p27Kip1 and p57Kip2 (Bryant et al., 2006; Lim et al., 2008a); and in some tissues, these proteins are required for cell differentiation (Bilodeau et al., 2009). Hence, it was possible that upregulation of these proteins in FAK mutant SCs could be the cause of premature upregulation of Krox 20.

Although p27Kip1 and p57Kip2 have been reported to, respectively, promote and inhibit differentiation of SCs in vitro (Heinen et al., 2008; Li et al., 2011), we have shown that overexpression of p27Kip1 does not promote differentiation or prime SCs for differ- 
entiation by dbcAMP, as measured by expression of periaxin (Fig. 5). Furthermore, p27Kip1 overexpression does not affect expression of Krox20 (data not shown). Consistent with these observations, examination of transverse sciatic nerve sections of 8-week-old p27Kip1 mutant mice showed that p27Kip1 is not required for SC differentiation in vivo (Fig. $7 A a, c)$. Furthermore, overexpression of p57Kip2 in vitro did not prime or promote SC differentiation (Fig. $7 B$; data not shown). This suggests that premature upregulation of these Kip proteins in FAK mutant SCs in vivo is a consequence rather than a cause of the premature initiation of differentiation.

We wished to address the apparent paradox that, although early differentiation markers were prematurely expressed in vivo by FAK mutant SCs, these cells did not go on to myelinate. One possibility was that prematurely upregulated differentiation markers could inhibit further differentiation. We investigated this hypothesis in vitro and in vivo.

p27Kip1 overexpression does not inhibit the differentiation of cultured SCs (Fig. 5). Nevertheless, it has been reported that aberrantly overexpressed $\mathrm{p} 27 \mathrm{Kip} 1 \mathrm{in}-$ hibits SC radial sorting in vivo (Porrello et al., 2014). To determine whether premature upregulation of p27Kip1 might contribute to the sorting defect in the FAK mutant SC phenotype in vivo, we crossed $F A K^{f l / f l}:$ p27Kip1 mice with $F A K^{f l /+}$ : p27Kip1 $1^{-/+}: \mathrm{CNP}-\mathrm{Cre}^{-/+}$mice and examined transverse sciatic nerve sections of 8 -week-old progeny. However, the radial sorting defect that we reported previously in FAK mutant sciatic nerves is not rescued in FAK:p27Kip1 double mutants (Fig. 7Ab,d) (Grove et al., 2007). Further, p57Kip2 has been reported to inhibit SC differentiation in vitro (Heinen et al., 2008); and in P5 sciatic nerves, p57Kip2 levels in FAK mutant SC nuclei remained elevated compared with controls (Fig. 7C).

However, differentiation of SCs overexpressing p57Kip2 in vitro was indistinguishable from that of controls (Fig. 7B).

Hence, our data suggest that premature expression of either p27Kip1 or p57Kip2 in FAK mutant SCs is unlikely to explain why these cells do not myelinate in vivo. Overall, these data suggest that $\mathrm{p} 27 \mathrm{Kip} 1$ and $\mathrm{p} 57 \mathrm{Kip} 2$ regulate Schwann cell proliferation rather than differentiation during SC development.

\section{SCs without FAK can proliferate normally and myelinate on mature BL}

Thus far, our data are consistent with the view that the defective proliferation and differentiation of FAK mutant SCs in vivo were due to their aberrant response to fragmentary BL during radial sorting and the promyelination phase of peripheral nerve myelination. If this were the case, a prediction would be that mutant SCs should behave normally in vivo in response to a mature BL.
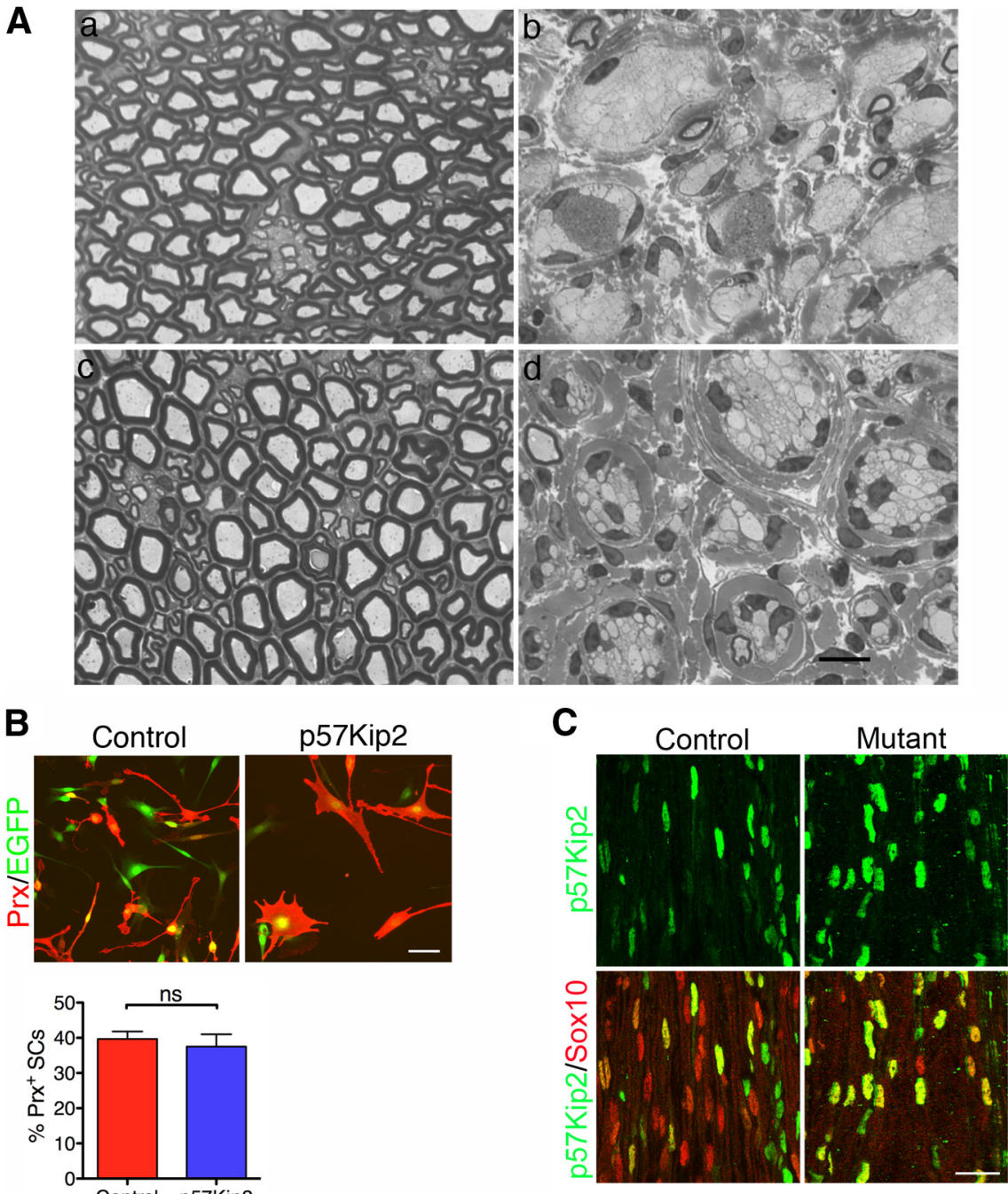

Figure 7. SC differentiation is not regulated by p27Kip1 or p57Kip2.A, Light microscopy of transverse sections $(1 \mu \mathrm{m})$ of sciatic nerves stained with toluidine blue from 2-month-old mice with the following genotypes: $\boldsymbol{A a}$, wild-type control; $\boldsymbol{A b}, F A K^{A / f f}: C N P$ ablation of 27 Kip 1 does not rescue this phenotype $(\boldsymbol{A d})$. Scale bar $10 \mu \mathrm{m}$. B . Primary rat SC expressing exogenous EGFP (control) or EGFP + p57Kip2 (p57Kip2) were seeded on high LN ( $5 \mu \mathrm{g} / \mathrm{ml})$, differentiated for $48 \mathrm{~h}$ with dbcAMP ( $1 \mathrm{~mm})$, and immunostained for periaxin (Prx) to assess differentiation. Control and p57Kip2-overexpressing Schwann cells differentiated equally well. Values are mean \pm SEM; two experiments, two coverslips per experiment. ns, Not significant (unpaired Student's $t$ test). Scale bar, 50 $\mu \mathrm{m}$. C, $P 5$ longitudinal sciatic nerve sections coimmunostained for p57Kip2 and Sox 10 to identify SC nuclei. p57Kip2 is expressed in both mutant control SC nuclei. Scale bar, $25 \mu \mathrm{m}$. Genotypes: control, FAK ${ }^{f / f f}$ or $F A K^{f / /+} ;$ mutant, $F A K^{f / f / l}: C N P-C r e^{-/+}$

To test this hypothesis, we used the regenerating peripheral nerve crush paradigm. After nerve crush SCs sequentially dedifferentiate, proliferate, redifferentiate and myelinate in Bands of Bungner, which are surrounded by the original mature SC BL. Little, if any, radial sorting of axons is required; however, to progress to myelination, promyelinating SCs must fully envelop associated axons in 1:1 relationships, a step at which FAK mutant SCs are defective during development (Ide, 1996; Nguyen et al., 2002; Chen et al., 2007) (Fig. 2). Hence, to determine whether FAK mutant SCs respond normally to mature BL in vivo, we assessed the ability of SCs in which FAK was ablated in the adult to proliferate and progress from promyelination to myelination on mature BL after sciatic nerve crush.

Control or $F A K^{f l / f l}: P L P$-Cre-Ert2 mice were treated with tamoxifen; and 4 months after treatment, one sciatic nerve of each mouse was crushed. The controls for the crush were treated with 

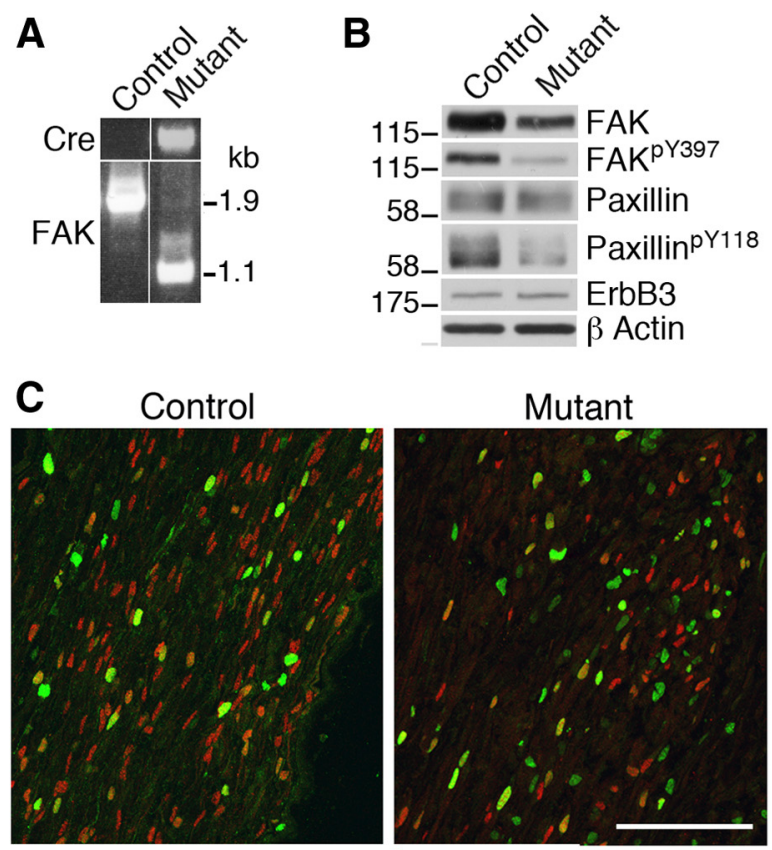

D

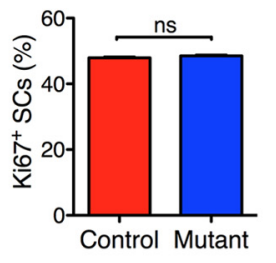

Ki67/Sox10

E

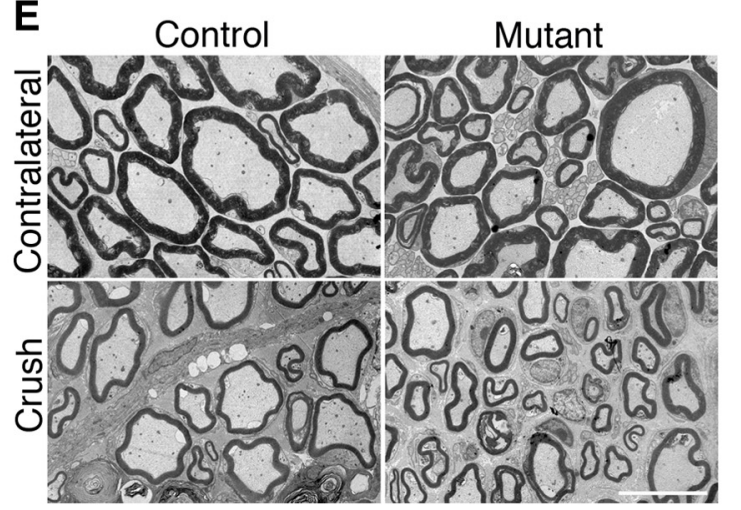

$\mathbf{F}$

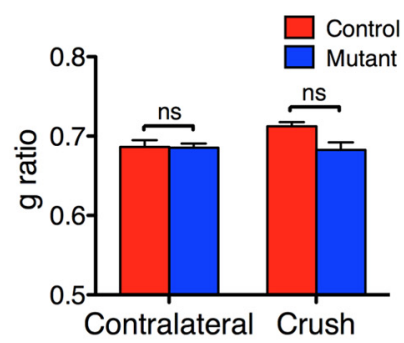

Figure 8. Adult SCs lacking FAK can proliferate and myelinate normally after sciatic nerve crush. Cre-mediated recombination was induced in 6-week-old control and mutant mice by tamoxifen injection. Sciatic nerves were crushed 4 months later and allowed to remyelinate. $\boldsymbol{A}$, Genotyping of sciatic nerve genomic DNA isolated from control and mutant mice revealed highly efficient Cre-mediated recombination. After PCR amplification and digestion with Hindlll, control mice had a diagnostic band of 1.9 $\mathrm{kb}$, whereas after recombination in the presence of Cre-ERT2, this band was shifted to $1.1 \mathrm{~kb}$. $\boldsymbol{B}$, Western blotting of lysates from control and mutant sciatic nerves showed reduced total FAK and reduced tyrosine phosphorylation of FAK $\left(\mathrm{Y}^{397}\right)$ and its target paxillin $\left(\mathrm{Y}^{118}\right)$. Actin and ErbB3 were loading controls. Molecular masses are shown in kilodaltons. C, D, Control and mutant SCS proliferate similarly $7 \mathrm{~d}$ after crush distal to the crush site. Longitudinal sciatic nerve sections were immunostained for the nuclear markers Ki67 and Sox10. Scale bar, $100 \mu \mathrm{m}$. Values are mean $\pm \mathrm{SEM} ; n=2 ; 3$ sections per sciatic nerve. ns, Not significant by Student's $t$ test. $\boldsymbol{E}$, Electron micrographs of transverse sections of control and mutant sciatic nerves 8 weeks after crush. Comparison of control and mutant contralateral nerves shows that FAK is not required for myelin maintenance in the adult. Both control and mutant sciatic nerves were myelinated after crush, showing that FAK is not required for remyelination in the adult. Scale bar, 10 $\mu \mathrm{m} . \boldsymbol{F}$, Measurement of $\mathrm{g}$-ratios in uncrushed (contralateral) and crushed (distal) control and mutant sciatic nerves 8 weeks after crush. Loss of FAK in mature sciatic nerves does not affect the g-ratios, and crushed sciatic nerves remyelinate normally. Values are mean \pm SEM; $n=3$ mice, 120 measurements per mouse. ns, Not significant by Student's $t$ test. Genotypes: control mice, $F A K^{f l / f l}$; mutant mice, FAK ${ }^{A l f l}:$ PLP-Cre-ERT2.

tamoxifen and were FAK ${ }^{\text {fl/fl }}$ without Cre. However, we had compared tamoxifen-treated $\mathrm{FAK}^{\mathrm{fl} / \mathrm{fl}}$ with tamoxifen-treated $\mathrm{FAK}^{+/+}$ mice previously and found no difference in their ability to remyelinate after crush. Sciatic nerves were removed for analysis either $7 \mathrm{~d}$ later to assess SC proliferation or 8 weeks later for analysis of remyelination by electron microscopy. In each experiment, we checked the extent of recombination in sciatic nerves by PCR and Western blot analysis (Fig. $8 A, B$ ). PCR analysis of mutant sciatic nerves showed recombination similar to that observed in sciatic nerves of $F A K^{f l / f l}: C N P-C r e^{-/+}$mice (Grove et al., 2007) (Fig. 8A), and Western blotting showed that total FAK, autophosphorylated FAK and phosphorylated paxillin levels were substantially reduced in lysates from such sciatic nerves, consistent with the ablation of FAK in SCs (Fig. 8B).

Proliferation of control and mutant SCs after sciatic nerve crush was measured by immunostaining for the proliferation marker Ki67 and Sox10 to identify SC nuclei. Proliferation was not observed in contralateral sciatic nerves or in crushed sciatic nerves proximal to the crush site (data not shown). As predicted from our in vitro experiments in which FRNK SCs proliferated well on high LN, FAK mutant SC proliferation in vivo was substantial and not significantly different from control SC proliferation after sciatic nerve crush (Fig. 8D).

Interestingly, electron microscopic analysis and assessment of myelin thickness by measurement of g-ratios in uncrushed contralateral sciatic nerves showed that loss of FAK in adult Schwann cells did not affect myelin maintenance (Fig. 8E,F). Importantly, and in marked contrast to early development, there was no block at the promyelination stage after sciatic nerve crush, and FAK mutant SCs were able to myelinate as effectively as control SCs (Fig. $8 E, F)$. The fact that the crushed mutant nerve appeared to have a lower g-ratio (although not significantly lower) than the uncrushed contralateral nerve may point to a possible role for FAK in regulating myelin thickness after radial sorting has occurred. Nevertheless, these data support the hypothesis that FAK is required for the correct regulation of SC proliferation and differentiation only when the BL is limiting and that once the $\mathrm{BL}$ is mature FAK is not required for remyelination.

\section{Discussion}

Here we show that FAK has a critical role in the response of SCs to limiting BL by promoting proliferation and preventing premature SC differentiaton. FAK is required to promote not only the proliferation of immature SCs (Grove et al., 2007) but also their spreading and timely differentiation on fragmentary BL during radial sorting. In contrast, FAK is not required by adult SCs on mature BL, either for myelin maintenance or for remyelination after sciatic nerve crush. FAK mutant or FRNK-expressing cells can display defective spreading in vitro (Ilić et al., 1995; Richardson et al., 1997). However, we show that the spreading defect in SCs is exacerbated as LN concentration is reduced, with profound effects on proliferation and differentiation. Our data thus support the hypothesis that the spreading defect of FAK mutant SCs on fragmentary BL is responsible for reduced proliferation and premature differen- 
tiation observed in vivo. Furthermore, our data suggest that reduction in contractile actomyosin, rather than $G_{1}$ arrest, primes SCs for differentiation.

The use of "low" and "high" LN substrates allowed us to model the response of SCs to fragmentary and mature BL in vitro because the behavior of control and FRNK SCs in vitro reflected the behavior of control and FAK mutant SCs on fragmentary and mature BL in vivo. In preliminary studies, we tested LN concentrations from 0.2 to $20 \mu \mathrm{g} / \mathrm{ml}$, and control SCs spread, polarized, extended, and differentiated similarly over this range. In contrast, FRNK SCs did not spread on $0.2 \mu \mathrm{g} / \mathrm{ml}$ LN but were maximally spread on $5 \mu \mathrm{g} / \mathrm{ml} \mathrm{LN} \mathrm{(Fig.} \mathrm{4),} \mathrm{and} \mathrm{they} \mathrm{displayed} \mathrm{a} \mathrm{progressive}$ change in spreading, proliferation, contractile actomyosin, and differentiation toward control values up to $5 \mu \mathrm{g} / \mathrm{ml} \mathrm{LN}$. Hence, we chose these two extreme conditions to model the response of SCs to LN.

The differences in the behavior of FAK mutant SCs on fragmentary versus mature $\mathrm{BL}$ in vivo are likely due to differences in either the levels or availability of LN. Support for this view is that $\mathrm{LN}$-dependent proliferation of SCs increases as the BL develops between E15.5 and E17.5 (Yu et al., 2005). LN $\gamma 1$ mutant SCs in vivo are defective in radial sorting due to a reduction in both proliferation and process extension around and into axon bundles (Yu et al., 2005). Furthermore, data in the same paper suggested that Oct6 and Krox20 were elevated in the LN $\gamma 1$ mutant compared with controls at E17.5 and P1, respectively, whereas Krox20 levels in the $\mathrm{LN} \gamma 1$ mutant were reduced at P7. These results are consistent with our data, suggesting that a spreading defect of LN $\gamma 1$ SCs can lead to premature initiation of differentiation and a proliferation defect.

We hypothesized that reduced spreading primes FAK mutant SCs for differentiation. It was also possible that, because p27Kip1 is prematurely upregulated in FAK mutant SCs in vivo, FAK might inhibit p27Kip1 accumulation, possibly via Skp2 or JAB1 (Bryant et al., 2006; Porrello et al., 2014); upregulation of p27Kip1 in FAK mutants might then in turn promote premature SC differentiation independently of SC spreading (Li et al., 2011). However, p27Kip1 (and p57Kip2) does not accumulate in FRNK SCs in the absence of dbcAMP in vitro (data not shown), suggesting that SC FAK does not directly regulate these Kips. Further, we have shown that $\mathrm{p} 27 \mathrm{Kip} 1$ is not required for SC differentiation in vivo, and overexpression of p27Kip1 (or p57Kip2) in vitro has little effect on promoting SC differentiation compared with loss of FAK function on low LN. Hence, we conclude that premature upregulation of p27Kip1 and p57Kip2 is a consequence rather than a cause of the premature initiation of differentiation of FAK mutant SCs in vivo. Our in vitro data show $\mathrm{G}_{1}$ arrest of SCs overexpressing these Kips, as expected (Fig. 5A; and data not shown) (Toyoshima and Hunter, 1994; Matsuoka et al., 1995), thus suggesting that prematurely upregulated Kips together with Krox20 (Parkinson et al., 2004) may play a role in maintaining the reduced proliferation of FAK mutant SCs in vivo.

The mechanisms that prime poorly spread FAK mutant SCs for differentiation are not yet known. However, the reduced spreading of FRNK SCs on low LN correlates with reduced actomyosin contractility. In other cell types, reduced size correlates with reduced actomyosin contractility (Chen et al., 2003; Théry, 2010) and poorly spread epidermal stem cells have an increased $\mathrm{F} / \mathrm{G}$ actin ratio compared with spread cells, thereby releasing a G-actin bound differentiation-inducing transcriptional cofactor (Connelly et al., 2010). Poorly spread mesenchymal stem cells also have reduced actomyosin con- tractility, which also changes their differentiation fate (McBeath et al., 2004).

Three lines of evidence suggest a role for reduced actomyosin contractility in priming FAK mutant SCs for differentiation. First, at low density on low LN, FRNK SCs are highly sensitive to dbcAMP-mediated differentiation, whereas control and p27Kip 1 overexpressing SCs differentiate poorly, independently of $\mathrm{G}_{1}$ arrest. FRNK SCs lack contractile actomyosin and FAs, but in contrast these are abundant in control and p27Kip1-overexpressing SCs. Further, FRNK SCs at low density on high LN are well spread, contain contractile actomyosin and FAs, and differentiate poorly, similar to controls. Second, at high density, FRNK SCs, control, and p27Kip1 overexpressors all differentiate well on high or low LN, and all have low indicators of contractility. Third, in work by others, reduced contractility caused by inhibition of MLCK promotes SC differentiation (Vicente-Manzanares et al., 2009; Leitman et al., 2011).

In spreading/migrating cells, the formation of contractile actomyosin requires not only myosin II activity, but also integrin activation at NAs, which promotes cell spreading and NA linkage to F actin (Giannone et al., 2003; Ziegler et al., 2008; Parsons et al., 2010; Wang et al., 2012; Burridge and Wittchen, 2013). Although important for adhesion maturation, myosin II is not required for adhesion formation or integrin activation and linkage to $\mathrm{F}$ actin (Choi et al., 2008; Parsons et al., 2010). Hence, cells could have active myosin II but low contractility. In other cell types, FAK localizes to NAs, where it promotes inside-out integrin activation and cell spreading (Hsia et al., 2003; Serrels et al., 2007, 2010; Michael et al., 2009; Lawson et al., 2012). With less ECM, insideout activation becomes relatively more important compared with outside-in activation of integrins (Olsen and Ffrench-Constant, 2005). Similarly, we find that, when LN concentration is relatively low, FAK becomes more important for SC spreading and the formation of FAs and contractile actomyosin. Hence, we propose that FAK might function at NAs in SCs in promoting insideout activation of integrins, such that, on fragmentary BL or low $\mathrm{LN}$, it is required for integrin activation, whereas on mature BL or high LN, it is not.

It is also possible that elevated cAMP contributes to the FAK mutant phenotype. FAK promotes cell-spreading through localized down-regulation of cAMP (Serrels et al., 2010), and cAMP inhibits cell contractility by inhibiting both RhoA and MLCK through PKA-mediated phosphorylation, thereby inhibiting myosin II activation (Howe, 2004; Oishi et al., 2012). Hence, some of the effects of FAK loss on SC spreading, differentiation, and probably contractility could be due to increased levels of cAMP. In support of this, upregulation of PKA activity in SCs by deletion of Prka1a results in reduced spreading and a radial sorting defect (Guo et al., 2013). An argument against this possibility is that FRNK SCs have normal levels of myosin II activity and also do not differentiate in the absence of exogenous dbAMP.

In conclusion, our data suggest the following. FAK promotes the spreading and contractility of SCs on fragmentary BL to make them receptive to proliferation signals and refractory to differentiation signals (independent of $\mathrm{G}_{1}$ status). Once $\mathrm{SCs}$ reach high density, their reduced contractility promotes sensitivity to cAMP, following which the Kips and Krox20 are upregulated, thus driving permanent cycle exit. In FAK mutants, an aberrant reduction in size and contractility of SCs makes them unreceptive to proliferative signals and sensitizes them to differentiation signals at low density, thus prompting upregulation of the Kips and Krox20 and permanent cell-cycle exit. This growth arrest at abnormally low SC density could potentially lead either to failure to reach 
sufficient density to trigger radial sorting (Webster, 1971; Martin and Webster, 1973) or to insufficient SCs to complete radial sorting (Grove et al., 2007).

Although differentiation and radial sorting normally occur at high SC density, our data indicate that the initiation of differentiation does not in itself trigger radial sorting, and are consistent with an older model whereby radial process extension is triggered by high SC density (Webster, 1971; Martin and Webster, 1973). Thus, at E18.5, when control and mutant SCs are at similar density, both have similar limited radial process extension (Grove et al., 2007). However, the density of FAK mutant SCs decreases over time due to their deficient proliferation, whereas control SC density increases; this would be predicted to result in reduced and increased radial process extension, respectively, which is what we observe. Thus, FAK may coordinate SC differentiation and radial process extension on fragmentary BL by promoting SC proliferation and high density before differentiation.

\section{References}

Beggs HE, Schahin-Reed D, Zang K, Goebbels S, Nave KA, Gorski J, Jones KR, Sretavan D, Reichardt LF (2003) FAK deficiency in cells contributing to the basal lamina results in cortical abnormalities resembling congenital muscular dystrophies. Neuron 40:501-514. CrossRef Medline

Besson A, Gurian-West M, Schmidt A, Hall A, Roberts JM (2004) p27Kip1 modulates cell migration through the regulation of RhoA activation. Genes Dev 18:862-876. CrossRef Medline

Bilodeau S, Roussel-Gervais A, Drouin J (2009) Distinct developmental roles of cell cycle inhibitors p57Kip2 and p27Kip1 distinguish pituitary progenitor cell cycle exit from cell cycle reentry of differentiated cells. Mol Cell Biol 29:1895-1908. CrossRef Medline

Blanchard AD, Sinanan A, Parmantier E, Zwart R, Broos L, Meijer D, Meier C, Jessen KR, Mirsky R (1996) Oct-6 (SCIP/Tst-1) is expressed in Schwann cell precursors, embryonic Schwann cells, and postnatal myelinating Schwann cells: comparison with Oct-1, Krox-20, and Pax-3. J Neurosci Res 46:630-640. CrossRef Medline

Bryant P, Zheng Q, Pumiglia K (2006) Focal adhesion kinase controls cellular levels of p27/Kip1 and p21/Cip1 through Skp2-dependent and -independent mechanisms. Mol Cell Biol 26:4201-4213. CrossRef Medline

Burridge K, Chrzanowska-Wodnicka M (1996) Focal adhesions, contractility, and signaling. Annu Rev Cell Dev Biol 12:463-518. CrossRef Medline

Burridge K, Wittchen ES (2013) The tension mounts: stress fibers as forcegenerating mechanotransducers. J Cell Biol 200:9-19. CrossRef Medline

Chen CS, Mrksich M, Huang S, Whitesides GM, Ingber DE (1997) Geometric control of cell life and death. Science 276:1425-1428. CrossRef Medline

Chen CS, Alonso JL, Ostuni E, Whitesides GM, Ingber DE (2003) Cell shape provides global control of focal adhesion assembly. Biochem Biophys Res Commun 307:355-361. CrossRef Medline

Chen ZL, Yu WM, Strickland S (2007) Peripheral regeneration. Annu Rev Neurosci 30:209-233. CrossRef Medline

Chernousov MA, Kaufman SJ, Stahl RC, Rothblum K, Carey DJ (2007) Alpha7betal integrin is a receptor for laminin-2 on Schwann cells. Glia 55:1134-1144. CrossRef Medline

Choi CK, Vicente-Manzanares M, Zareno J, Whitmore LA, Mogilner A, Horwitz AR (2008) Actin and alpha-actinin orchestrate the assembly and maturation of nascent adhesions in a myosin II motor-independent manner. Nat Cell Biol 10:1039-1050. CrossRef Medline

Connelly JT, Gautrot JE, Trappmann B, Tan DW, Donati G, Huck WT, Watt FM (2010) Actin and serum response factor transduce physical cues from the microenvironment to regulate epidermal stem cell fate decisions. Nat Cell Biol 12:711-718. CrossRef Medline

Dalton S (2013) $\mathrm{G}_{1}$ compartmentalization and cell fate coordination. Cell 155:13-14. CrossRef Medline

Dong Z, Dean C, Walters JE, Mirsky R, Jessen KR (1997) Response of Schwann cells to mitogens in vitro is determined by pre-exposure to serum, time in vitro, and developmental age. Glia 20:219-230. CrossRef Medline

Fero ML, Rivkin M, Tasch M, Porter P, Carow CE, Firpo E, Polyak K, Tsai LH, Broudy V, Perlmutter RM, Kaushansky K, Roberts JM (1996) A syndrome of multiorgan hyperplasia with features of gigantism, tumorigen- esis, and female sterility in p27(Kip1)-deficient mice. Cell 85:733-744. CrossRef Medline

Giannone G, Jiang G, Sutton DH, Critchley DR, Sheetz MP (2003) Talin1 is critical for force-dependent reinforcement of initial integrin-cytoskeleton bonds but not tyrosine kinase activation. J Cell Biol 163:409-419. CrossRef Medline

Giannone G, Dubin-Thaler BJ, Rossier O, Cai Y, Chaga O, Jiang G, Beaver W, Döbereiner HG, Freund Y, Borisy G, Sheetz MP (2007) Lamellipodial actin mechanically links myosin activity with adhesion-site formation. Cell 128:561-575. CrossRef Medline

Grove M, Komiyama NH, Nave KA, Grant SG, Sherman DL, Brophy PJ (2007) FAK is required for axonal sorting by Schwann cells. J Cell Biol 176:277-282. CrossRef Medline

Guo L, Lee AA, Rizvi TA, Ratner N, Kirschner LS (2013) The Protein Kinase A regulatory subunit R1A (Prkar1a) plays critical roles in peripheral nerve development. J Neurosci 33:17967-17975. CrossRef Medline

Heinen A, Kremer D, Göttle P, Kruse F, Hasse B, Lehmann H, Hartung HP, Küry P (2008) The cyclin-dependent kinase inhibitor p57kip2 is a negative regulator of Schwann cell differentiation and in vitro myelination. Proc Natl Acad Sci U S A 105:8748-8753. CrossRef Medline

Howe AK (2004) Regulation of actin-based cell migration by cAMP/PKA. Biochim Biophys Acta 1692:159-174. CrossRef Medline

Hsia DA, Mitra SK, Hauck CR, Streblow DN, Nelson JA, Ilić D, Huang S, Li E, Nemerow GR, Leng J, Spencer KS, Cheresh DA, Schlaepfer DD (2003) Differential regulation of cell motility and invasion by FAK. J Cell Biol 160:753-767. CrossRef Medline

Ide C (1996) Peripheral nerve regeneration. Neurosci Res 25:101-121. CrossRef Medline

Ilić D, Furuta Y, Kanazawa S, Takeda N, Sobue K, Nakatsuji N, Nomura S, Fujimoto J, Okada M, Yamamoto T (1995) Reduced cell motility and enhanced focal adhesion contact formation in cells from FAK-deficient mice. Nature 377:539-544. CrossRef Medline

Jessen KR, Mirsky R (2005) The origin and development of glial cells in peripheral nerves. Nat Rev Neurosci 6:671-682. CrossRef Medline

Kreipe H, Heidebrecht HJ, Hansen S, Röhlk W, Kubbies M, Wacker HH, Tiemann M, Radzun HJ, Parwaresch R (1993) A new proliferationassociated nuclear antigen detectable in paraffin-embedded tissues by the monoclonal antibody Ki-S1. Am J Pathol 142:3-9. Medline

Lawson C, Schlaepfer DD (2012) Integrin adhesions: who's on first? What's on second? Connections between FAK and talin. Cell Adh Migr 6:302306. CrossRef Medline

Lawson C, Lim ST, Uryu S, Chen XL, Calderwood DA, Schlaepfer DD (2012) FAK promotes recruitment of talin to nascent adhesions to control cell motility. J Cell Biol 196:223-232. CrossRef Medline

Leitman EM, Tewari A, Horn M, Urbanski M, Damanakis E, Einheber S, Salzer JL, de Lanerolle P, Melendez-Vasquez CV (2011) MLCK regulates Schwann cell cytoskeletal organization, differentiation and myelination. J Cell Sci 124:3784-3796. CrossRef Medline

Li H, Yang H, Liu Y, Huan W, Zhang S, Wu G, Lu Q, Wang Q, Wang Y (2011) The cyclin-dependent kinase inhibitor $\mathrm{p} 27$ (Kip1) is a positive regulator of Schwann cell differentiation in vitro. J Mol Neurosci 45:277-283. CrossRef Medline

Lim ST, Chen XL, Lim Y, Hanson DA, Vo TT, Howerton K, Larocque N, Fisher SJ, Schlaepfer DD, Ilic D (2008a) Nuclear FAK promotes cell proliferation and survival through FERM-enhanced p53 degradation. Mol Cell 29:9-22. CrossRef Medline

Lim Y, Lim ST, Tomar A, Gardel M, Bernard-Trifilo JA, Chen XL, Uryu SA, Canete-Soler R, Zhai J, Lin H, Schlaepfer WW, Nalbant P, Bokoch G, Ilić D, Waterman-Storer C, Schlaepfer DD (2008b) PyK2 and FAK connections to p190Rho guanine nucleotide exchange factor regulate RhoA activity, focal adhesion formation, and cell motility. J Cell Biol 180:187-203. CrossRef Medline

Martin JR, Webster HD (1973) Mitotic Schwann cells in developing nerve: their changes in shape, fine structure, and axon relationships. Dev Biol 32:417-431. CrossRef Medline

Matsuoka S, Edwards MC, Bai C, Parker S, Zhang P, Baldini A, Harper JW, Elledge SJ (1995) p57Kip2, a structurally distinct member of the p21CIP1 Cdk inhibitor family, is a candidate tumor suppressor gene. Genes Dev 9:650-662. CrossRef Medline

McBeath R, Pirone DM, Nelson CM, Bhadriraju K, Chen CS (2004) Cell shape, cytoskeletal tension, and RhoA regulate stem cell lineage commitment. Dev Cell 6:483-495. CrossRef Medline 
McLean GW, Komiyama NH, Serrels B, Asano H, Reynolds L, Conti F, HodivalaDilke K, Metzger D, Chambon P, Grant SG, Frame MC (2004) Specific deletion of focal adhesion kinase suppresses tumor formation and blocks malignant progression. Genes Dev 18:2998-3003. CrossRef Medline

Michael KE, Dumbauld DW, Burns KL, Hanks SK, García AJ (2009) Focal adhesion kinase modulates cell adhesion strengthening via integrin activation. Mol Biol Cell 20:2508-2519. CrossRef Medline

Morgan L, Jessen KR, Mirsky R (1991) The effects of cAMP on differentiation of cultured Schwann cells: progression from an early phenotype $(04+)$ to a myelin phenotype (P0+, GFAP-, N-CAM-, NGF-receptor-) depends on growth inhibition. J Cell Biol 112:457-467. CrossRef Medline

Mummery CL, van Rooijen MA, van den Brink SE, de Laat SW (1987) Cell cycle analysis during retinoic acid induced differentiation of a human embryonal carcinoma-derived cell line. Cell Differ 20:153-160. CrossRef Medline

Nguyen QT, Sanes JR, Lichtman JW (2002) Pre-existing pathways promote precise projection patterns. Nat Neurosci 5:861-867. CrossRef Medline

Oishi A, Makita N, Sato J, Iiri T (2012) Regulation of RhoA signaling by the cAMP-dependent phosphorylation of RhoGDIalpha. J Biol Chem 287: 38705-38715. CrossRef Medline

Olsen IM, Ffrench-Constant C (2005) Dynamic regulation of integrin activation by intracellular and extracellular signals controls oligodendrocyte morphology. BMC Biol 3:25. CrossRef Medline

Parkinson DB, Dong Z, Bunting H, Whitfield J, Meier C, Marie H, Mirsky R, Jessen KR (2001) Transforming growth factor beta (TGFbeta) mediates Schwann cell death in vitro and in vivo: examination of c-Jun activation, interactions with survival signals, and the relationship of TGFbeta-mediated death to Schwann cell differentiation. J Neurosci 21:8572-8585. Medline

Parkinson DB, Dickinson S, Bhaskaran A, Kinsella MT, Brophy PJ, Sherman DL, Sharghi-Namini S, Duran Alonso MB, Mirsky R, Jessen KR (2003) Regulation of the myelin gene periaxin provides evidence for Krox-20independent myelin-related signalling in Schwann cells. Mol Cell Neurosci 23:13-27. CrossRef Medline

Parkinson DB, Bhaskaran A, Droggiti A, Dickinson S, D’Antonio M, Mirsky R, Jessen KR (2004) Krox-20 inhibits Jun-NH2-terminal kinase/c-Jun to control Schwann cell proliferation and death. J Cell Biol 164:385-394. CrossRef Medline

Parsons JT, Horwitz AR, Schwartz MA (2010) Cell adhesion: integrating cytoskeletal dynamics and cellular tension. Nat Rev Mol Cell Biol 11:633643. CrossRef Medline

Pasapera AM, Schneider IC, Rericha E, Schlaepfer DD, Waterman CM (2010) Myosin II activity regulates vinculin recruitment to focal adhesions through FAK-mediated paxillin phosphorylation. J Cell Biol 188: 877-890. CrossRef Medline

Pear WS, Nolan GP, Scott ML, Baltimore D (1993) Production of high-titer helper-free retroviruses by transient transfection. Proc Natl Acad Sci U S A 90:8392-8396. CrossRef Medline

Pear WS, Miller JP, Xu L, Pui JC, Soffer B, Quackenbush RC, Pendergast AM, Bronson R, Aster JC, Scott ML, Baltimore D (1998) Efficient and rapid induction of a chronic myelogenous leukemia-like myeloproliferative disease in mice receiving P210 bcr/abl-transduced bone marrow. Blood 92:3780-3792. Medline

Pellegatta M, De Arcangelis A, D'Urso A, Nodari A, Zambroni D, Ghidinelli M, Matafora V, Williamson C, Georges-Labouesse E, Kreidberg J, Mayer U, McKee KK, Yurchenco PD, Quattrini A, Wrabetz L, Feltri ML (2013) alpha6betal and alpha7betal integrins are required in Schwann cells to sort axons. J Neurosci 33:17995-18007. CrossRef Medline

Pereira JA, Benninger Y, Baumann R, Gonçalves AF, Ozçelik M, Thurnherr T, Tricaud N, Meijer D, Fässler R, Suter U, Relvas JB (2009) Integrinlinked kinase is required for radial sorting of axons and Schwann cell remyelination in the peripheral nervous system. J Cell Biol 185:147-161. CrossRef Medline

Peters A, Muir AR (1959) The relationship between axons and Schwann cells during development of peripheral nerves in the rat. Q J Exp Physiol Cogn Med Sci 44:117-130. Medline

Porrello E, Rivellini C, Dina G, Triolo D, Del Carro U, Ungaro D, Panattoni M, Feltri ML, Wrabetz L, Pardi R, Quattrini A, Previtali SC (2014) Jab1 regulates Schwann cell proliferation and axonal sorting through p27. J Exp Med 211:29-43. CrossRef Medline
Richardson A, Parsons T (1996) A mechanism for regulation of the adhesion-associated protein tyrosine kinase pp125FAK. Nature 380:538 540. CrossRef Medline

Richardson A, Malik RK, Hildebrand JD, Parsons JT (1997) Inhibition of cell spreading by expression of the C-terminal domain of focal adhesion kinase (FAK) is rescued by coexpression of Src or catalytically inactive FAK: a role for paxillin tyrosine phosphorylation. Mol Cell Biol 17:6906-6914. Medline

Schaller MD (2010) Cellular functions of FAK kinases: insight into molecular mechanisms and novel functions. J Cell Sci 123:1007-1013. CrossRef Medline

Serrels B, Serrels A, Brunton VG, Holt M, McLean GW, Gray CH, Jones GE, Frame MC (2007) Focal adhesion kinase controls actin assembly via a FERM-mediated interaction with the Arp $2 / 3$ complex. Nat Cell Biol 9:1046-1056. CrossRef Medline

Serrels B, Sandilands E, Serrels A, Baillie G, Houslay MD, Brunton VG, Canel M, Machesky LM, Anderson KI, Frame MC (2010) A complex between FAK, RACK1, and PDE4D5 controls spreading initiation and cancer cell polarity. Curr Biol 20:1086-1092. CrossRef Medline

Sherman DL, Wu LM, Grove M, Gillespie CS, Brophy PJ (2012a) Drp2 and periaxin form Cajal bands with dystroglycan but have distinct roles in Schwann cell growth. J Neurosci 32:9419-9428. CrossRef Medline

Sherman DL, Krols M, Wu LM, Grove M, Nave KA, Gangloff YG, Brophy PJ (2012b) Arrest of myelination and reduced axon growth when Schwann cells lack mTOR. J Neurosci 32:1817-1825. CrossRef Medline

Tamura M, Gu J, Matsumoto K, Aota S, Parsons R, Yamada KM (1998) Inhibition of cell migration, spreading, and focal adhesions by tumor suppressor PTEN. Science 280:1614-1617. CrossRef Medline

Tang X, Falls DL, Li X, Lane T, Luskin MB (2007) Antigen-retrieval procedure for bromodeoxyuridine immunolabeling with concurrent labeling of nuclear DNA and antigens damaged by $\mathrm{HCl}$ pretreatment. J Neurosci 27:5837-5844. CrossRef Medline

Théry M (2010) Micropatterning as a tool to decipher cell morphogenesis and functions. J Cell Sci 123:4201-4213. CrossRef Medline

Topilko P, Levi G, Merlo G, Mantero S, Desmarquet C, Mancardi G, Charnay P (1997) Differential regulation of the zinc finger genes Krox-20 and Krox-24 (Egr-1) suggests antagonistic roles in Schwann cells. J Neurosci Res 50:702-712. CrossRef Medline

Toyoshima H, Hunter T (1994) p27, a novel inhibitor of $G_{1}$ cyclin-Cdk protein kinase activity, is related to p21. Cell 78:67-74. CrossRef Medline

Vicente-Manzanares M, Ma X, Adelstein RS, Horwitz AR (2009) Nonmuscle myosin II takes centre stage in cell adhesion and migration. Nat Rev Mol Cell Biol 10:778-790. CrossRef Medline

Wang S, Watanabe T, Matsuzawa K, Katsumi A, Kakeno M, Matsui T, Ye F, Sato K, Murase K, Sugiyama I, Kimura K, Mizoguchi A, Ginsberg MH, Collard JG, Kaibuchi K (2012) Tiaml interaction with the PAR complex promotes talin-mediated Racl activation during polarized cell migration. J Cell Biol 199:331-345. CrossRef Medline

Webb DJ, Donais K, Whitmore LA, Thomas SM, Turner CE, Parsons JT, Horwitz AF (2004) FAK-Src signalling through paxillin, ERK and MLCK regulates adhesion disassembly. Nat Cell Biol 6:154-161. CrossRef Medline

Webster HD (1971) The geometry of peripheral myelin sheaths during their formation and growth in rat sciatic nerves. J Cell Biol 48:348-367. CrossRef Medline

Webster HD, Martin R, O’Connell MF (1973) The relationships between interphase Schwann cells and axons before myelination: a quantitative electron microscopic study. Dev Biol 32:401-416. CrossRef Medline

Yang D, Bierman J, Tarumi YS, Zhong YP, Rangwala R, Proctor TM, Miyagoe-Suzuki Y, Takeda S, Miner JH, Sherman LS, Gold BG, Patton BL (2005) Coordinate control of axon defasciculation and myelination by laminin-2 and -8. J Cell Biol 168:655-666. CrossRef Medline

Yu WM, Feltri ML, Wrabetz L, Strickland S, Chen ZL (2005) Schwann cellspecific ablation of laminin gammal causes apoptosis and prevents proliferation. J Neurosci 25:4463-4472. CrossRef Medline

Zetterberg A, Larsson O (1985) Kinetic analysis of regulatory events in $\mathrm{G}_{1}$ leading to proliferation or quiescence of Swiss 3T3 cells. Proc Natl Acad Sci U S A 82:5365-5369. CrossRef Medline

Ziegler WH, Gingras AR, Critchley DR, Emsley J (2008) Integrin connections to the cytoskeleton through talin and vinculin. Biochem Soc Trans 36:235-239. CrossRef Medline 